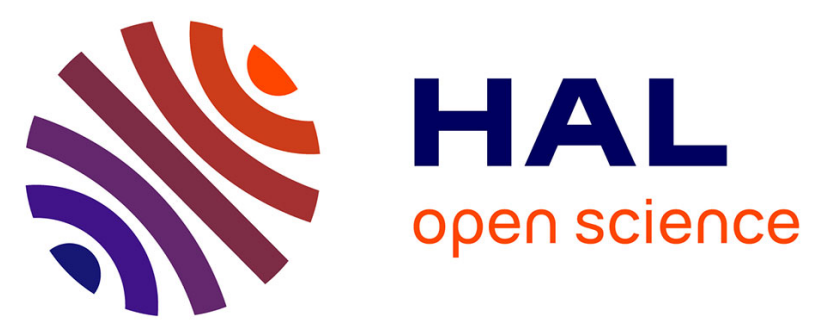

\title{
Amorphous material in experimentally deformed mafic rock and its temperature dependence: Implications for fault rheology during aseismic creep and seismic rupture
}

Sina Marti, Holger Stünitz, Renée Heilbronner, Oliver Plümper

\section{- To cite this version:}

Sina Marti, Holger Stünitz, Renée Heilbronner, Oliver Plümper. Amorphous material in experimentally deformed mafic rock and its temperature dependence: Implications for fault rheology during aseismic creep and seismic rupture. Journal of Structural Geology, 2020, 138, pp.104081. 10.1016/j.jsg.2020.104081 . insu-02893334

\section{HAL Id: insu-02893334 \\ https://hal-insu.archives-ouvertes.fr/insu-02893334}

Submitted on 2 Apr 2021

HAL is a multi-disciplinary open access archive for the deposit and dissemination of scientific research documents, whether they are published or not. The documents may come from teaching and research institutions in France or abroad, or from public or private research centers.
L'archive ouverte pluridisciplinaire HAL, est destinée au dépôt et à la diffusion de documents scientifiques de niveau recherche, publiés ou non, émanant des établissements d'enseignement et de recherche français ou étrangers, des laboratoires publics ou privés. 


\title{
Amorphous material in experimentally deformed mafic rock and its temperature dependence: Implications for fault rheology during aseismic creep and seismic rupture
}

\author{
Sina Marti ${ }^{\text {a,* }}$, Holger Stünitz ${ }^{\text {b,c }}$, Renée Heilbronner ${ }^{\mathrm{a}, \mathrm{b}}$, Oliver Plümper ${ }^{\mathrm{d}}$ \\ ${ }^{a}$ Department of Environmental Sciences, Basel University, Switzerland \\ ${ }^{\mathrm{b}}$ Department of Geosciences, University of Troms $\phi$, Norway \\ ${ }^{\mathrm{c}}$ Institut des Sciences de la Terre d'Orleans (ISTO), Université d'Orléans, France \\ ${ }^{\mathrm{d}}$ Department of Earth Sciences, Utrecht University, The Netherlands
}

A B S T R A C T

Amorphous materials are frequently observed in natural and experimentally produced fault rocks. Their common occurrence suggests that amorphous materials are of importance to fault zone dynamics. However, little is known about the physico-chemical impact of amorphous materials on fault rheology. Here we present deformation experiments on mafic fault rock, where amorphous material forms due to intense mechanical wear during the experiments. The experiments are run at temperatures from 300 to $600^{\circ} \mathrm{C}$, confining pressures of 0.5 or $1.0 \mathrm{GPa}$, and at constant displacement rates of $\left(\dot{d}_{a x}\right) 2 \cdot 10^{-7}, 2 \cdot 10^{-8}$ or $^{2} \cdot 10^{-9} \mathrm{~ms}{ }^{-1}$, resulting in bulk strain rates $(\dot{\gamma})$ of $\approx 3 \cdot 10^{-4}, 3 \cdot 10^{-5}$ and $3 \cdot 10^{-6} \mathrm{~s}^{-1}$. At these conditions, the mafic rock material undergoes intense brittle deformation and cataclastic flow, but sample strength significantly decreases with increasing temperatures - a feature commonly attributed to viscous deformation processes. Microstructural analyses show that after an initial stage of homogeneous cataclastic flow, strain localizes into narrow $(2-10 \mu \mathrm{m}$ wide) ultra-cataclastic bands that evolve into amorphous shear bands. With the data presented in this research paper, we argue that the temperature sensitivity recorded in the mechanical data is caused by viscous deformation of the amorphous material. We suggest that with the formation of amorphous materials during brittle deformation, fault rheology becomes significantly temperaturesensitive. This has important implications for our understanding of fault strength and weakening due to the presence of amorphous materials. In addition, weak material along faults will lead to stress concentrations that may trigger seismic rupture.

\section{Introduction}

Semi-brittle deformation in rocks is a mode of deformation between the brittle-ductile (BDT) and the brittle-viscous transitions (BVT; e.g. Kohlstedt et al., 1995, who use the term "brittle-plastic transition", BPT). While the BDT is only pressure dependent (e.g. Byerlee, 1968, Rutter, 1968), the BVT is primarily temperature dependent. Semi-brittle deformation is expected for the deeper parts of the upper to middle crust. Here, rocks achieve significant amounts of displacement without localized failure on discrete fracture surfaces. Instead deformation is largely accommodated by pervasive cataclastic flow. The change from localized brittle to de-localized semi-brittle flow is attributed to the circumstance that frictional sliding at elevated pressures requires higher stresses than the stresses needed to form new micro-cracks. The change from semi-brittle to viscous deformation is achieved by a number of deformation mechanisms in combination. Grain boundary sliding, crystal plasticity, and diffusive mass transfer all play a role to varying degree in the transition (e.g. Gratier et al., 1999; Bos and Spiers, 2001,
2002; Marti et al., 2017; Richter et al., 2018).

Laboratory experiments investigating rock deformation in the brittle field are usually performed at ambient temperatures, to sometimes up to $\sim 200{ }^{\circ} \mathrm{C}$ (e.g. Niemeijer et al., 2012; Brantut et al., 2013, and references therein). Brittle processes generally show low activation energies and hence have a low sensitivity on temperature. However, subcritical crack growth due to corrosion cracking, for example - a mechanism associated with the brittle field - is known to have a temperature and rate (i.e. time) dependencies (see e.g. the reviews of Anderson and Grew, 1977; Brantut et al., 2013). Additionally, brittle faulting is sometimes observed to be accompanied by (temperature sensitive) dissolution-precipitation creep, able to compete with other deformation mechanisms because of grain size reduction due to cataclasis, (e.g., Gratier and Gueydan, 2008, and references therein). The occurrence of amorphous material in brittle fault zones (e.g. Yund et al., 1990; Goldsby and Tullis, 2002; Janssen et al., 2010; Pec et al., 2012, 2016; Kirkpatrick et al., 2013; Hayward et al., 2016) may introduce further time and temperature-sensitivity to fault strength. 
The occurrence of amorphous material in seismically and aseismically sheared rocks has long been recognized and is reported in deformation experiments under a range of temperatures, normal stresses and displacement rates (e.g. Spray, 1987; Yund et al., 1990; Goldsby and Tullis, 2002; Di Toro et al., 2006; Niemeijer et al., 2011; Pec et al., 2012; Hayward et al., 2016). In nature, 'pseudotachylites', which are interpreted to have formed during seismic rupture and melt generation due to frictional heat, are the most common of amorphous material within fault zones (e.g. Sibson, 1975; Camacho et al., 1995; Obata and Karato, 1995; Curewitz and Karson, 1999; Austrheim and Andersen, 2004; Scambelluri et al., 2017). The great majority of pseudotachylite descriptions in fault zones suggest an origin via frictional melting (melt-origin). However, Curewitz \& Karson (1999) present a well-documented case for an ultracataclastic pre-stage (crush-origin) prior to pseudotachylite formation by frictional melting. Pseudotachylite formation without any contribution from frictional melting has also been proposed by e.g., Wenk (1978); Janssen et al. (2010); and Pec et al. (2012), 2016) but unfortunately, microstructural characteristics to distinguish a melt-origin from potential crush-origin type pseudotachylite have been difficult to define. Investigations of the origins of amorphous materials within fault zones are challenged by the low preservation of small amounts of amorphous material, especially under hydrothermal conditions typical for fault zones. Experimental studies can help to overcome this problem as alteration and overprinting are avoided.

Despite the wide-spread occurrence of amorphous materials in faults, the rheological impact on fault strength is not well determined. The deformation of amorphous materials may be described in terms of the time-scale of structural relaxation, which determines the transition from liquid (relaxed) to glassy (i.e. solid, unrelaxed) behaviour (e.g. Dingwell and Webb, 1989). The processes by which a glassy (solid amorphous) material is deformed are relatively complicated; unlike crystalline materials, amorphous materials lack a long-range ordered crystal structure suitable for dislocation creep, or grain boundaries that serve as fast diffusional pathways. However, amorphous materials typically show a rheological transition from a solid glassy behavior to a viscous fluid-like behavior at the "glass transition temperature" $\left(\mathrm{T}_{\mathrm{g}}\right)$. The $\mathrm{T}_{\mathrm{g}}$ is marked by a change in physical properties such as viscosity, shear modulus, heat capacity etc. (e.g. Ojovan, 2008), with the rheology of the amorphous material being highly sensitive to temperatures above the $T_{g}$ and less sensitive below $\mathrm{T}_{\mathrm{g}}$.

Although there is the possibility of rate- and temperature-sensitive processes contributing to brittle rock deformation, little is described about them from laboratory experiments (e.g, Chester and Higgs, 1992; Blanpied et al., 1995). For the activation of viscous (i.e. temperature-activated) deformation at laboratory strain rates it is usually necessary to make use of the rate increase of temperature-activated processes with higher temperatures.

In the study presented here, diabase rock material is deformed within the semi-brittle field, at intermediate temperatures of $300-600{ }^{\circ} \mathrm{C}$. Although the microstructure of the sample is dominated by brittle deformation, the samples show decreasing strength with increasing temperature - a behavior typical for viscous deformation. We suggest that in this intermediate temperature range, temperature-activated processes take place at laboratory time-scales, thus enabling us to investigate the contribution of these processes to the rheology of fault zones within the brittle- to semi-brittle field.

\section{Materials and methods}

\subsection{Sample material and sample assembly}

Experiments were performed on rock powder (grain size fraction $\leq$ $125 \mu \mathrm{m}$ ) prepared from Maryland Diabase, with an approximate modal composition of plagioclase: 57 vol- $\%$, clinopyroxene: 32 vol- $\%$, orthopyroxene: 8 vol- $\%$, accessories (Qz, Kfs, Ilm, Mag, Bt, Ap): 3 vol-\% (Marti et al., 2017/2018).
Most samples were prepared by placing $0.11 \mathrm{~g}$ of rock powder, with $0.2 \mu \mathrm{l}(0.18 \mathrm{wt} \%) \mathrm{H}_{2} \mathrm{O}$ added, between alumina forcing blocks pre-cut at $45^{\circ}$ (Fig. 1). In this way, a layer of rock material with a starting thickness $\sim 0.8 \mathrm{~mm}$ is obtained. The alumina forcing blocks are cylindrical and $6.33 \mathrm{~mm}$ in diameter. One experiment (nr. 475) was performed on a cored cylinder of intact Maryland Diabase, with a diameter of $6.55 \mathrm{~mm}$, a length of $15.80 \mathrm{~mm}$, and $0.18 \mathrm{wt} \% \mathrm{H}_{2} \mathrm{O}$ added to the sample. More experimental details can be found in Appendix A1.

\subsection{Experimental conditions}

Experiments were performed using the Griggs-type deformation apparatus at the University of Troms $\varnothing$, Norway. Experiments were run at temperatures (T) of 300,500 and $600{ }^{\circ} \mathrm{C}$ and at confining pressures (Pc) of 0.5 or $1.0 \mathrm{GPa}$. General shear type of flow is achieved by using the $45^{\circ}$ pre-cut setup. Axial displacement rates $\left(\dot{d}_{a x}\right)$ were held constant at 2 $\cdot 10^{-7}, 2 \cdot 10^{-8}$ or $2 \cdot 10^{-9} \mathrm{~m} \mathrm{~s}^{-1}$, resulting in bulk strain rates $(\dot{\gamma})$ of $\approx 3$ $\cdot 10^{-4}, 3 \cdot 10^{-5}$ and $3 \cdot 10^{-6} \mathrm{~s}^{-1}$ assuming homogeneous sample deformation. Table 1 lists experiments and experimental conditions. For the general shear experiments, axial displacement $\left(d_{a x}\right)$ translates to shear displacement $\left(d_{s}\right)$ according to:

$d_{s}=\frac{d_{a x}-\left(d_{a x} \cdot(t h 0-t h F)\right)}{\cos \left(45^{\circ}\right)}$

where: $t h_{0}=$ initial shear zone thickness; $t h_{F}=$ shear zone thickness at the experiment end; $45^{\circ}$ is the angle of forcing block pre-cut (Fig. 1c). Details concerning conversion of mechanical data can be found in Appendix A2.

\subsection{Microstructural analysis}

\subsubsection{Electron microscopy}

After the experiments, samples were immersed in epoxy, cut parallel (in some cases also normal) to the shear direction, and prepared as polished thin sections. Scanning electron microscope (SEM) analyses were performed with a Philips XL30 ESEM at the Basel University "Swiss Nano Imaging" (SNI) facility. Focussed ion beam (FIB) foils were prepared using a FEI Helios Nano Lab G3 at Utrecht University, on sections normal to shear direction, such that the foil is parallel to the shear direction. (Scanning) transmission electron microscope ((S)TEM) analyses were performed at Utrecht University using a FEI Talos 200FX equipped with a high-sensitivity Super-EDX system, and at the University of Minneapolis, using a FEI Tecnai 12. TEM images were recorded in bright-field (BF) and STEM images were acquired in dark field (DF) and high-angle annular dark-field (HAADF) modes.

\subsection{Image orientation and definitions}

If not stated otherwise, micrographs are oriented with the shear zone boundaries horizontal and with a dextral sense of shear. Terminology used to describe stress-displacement curves is given in Fig. $1 \mathrm{~d}$.

We consider cataclastic flow as "a deformational process involving initial granulation of grains by microcracking, leading to frictional sliding, dilatancy, and rigid-body rotation among grain fragments, grains or groups of grains." according to the definition by Schmid and Handy (1991).

Shear zone or bulk shear zone: The term "shear zone", in the reference system of our samples, is used to refer to the layer of rock material placed between the $45^{\circ}$ pre-cut forcing block which gets sheared as a bulk during the experiment. It does not imply any specific deformation mechanism or deformation regime (brittle or viscous).

The term "shear band" is used to refer to a thin zone (within the bulk shear zone) of high and localized shear strain accommodation - as opposed to a "shear fracture", which accommodates displacement along a surface without any obvious distribution of strain within a volume (discernible at SEM resolution). The term shear band is used without 

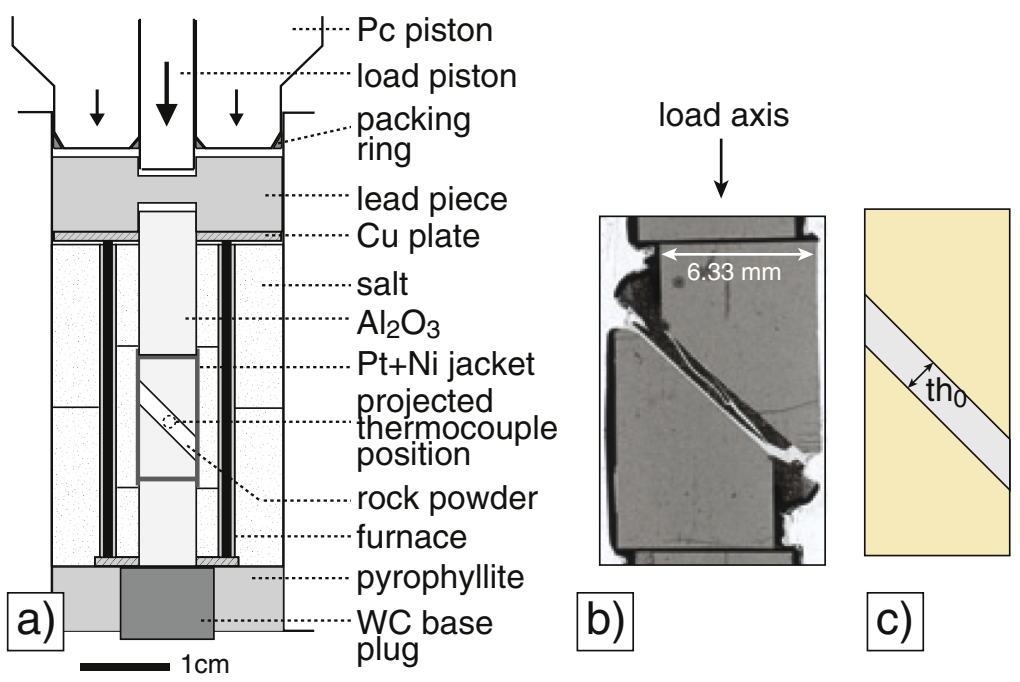

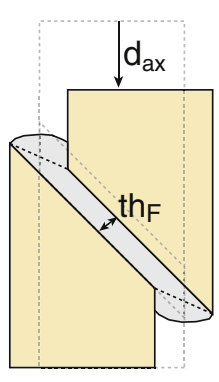

c)

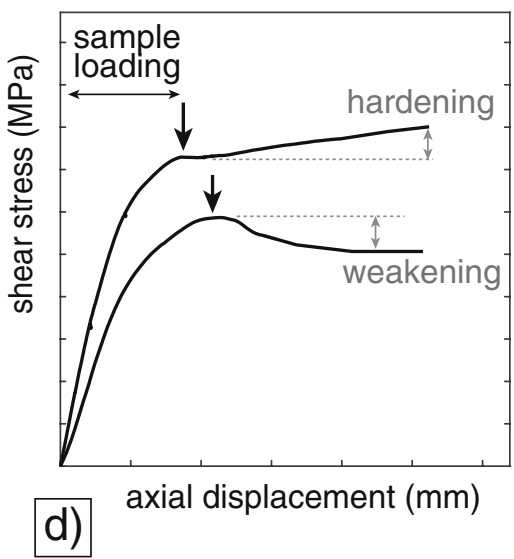

Fig. 1. a) Sample assembly. b) Scanned thin section (plane polarized light) of a sample after deformation. Cracking sometimes occurs during de-pressurization to room conditions after experiment termination. c) Sketch of a sample at experiment start (left) and end (right), showing the shear displacement and the thinning of the shear zone. th $\mathrm{h}_{0}=$ initial shear zone thickness, $\mathrm{th}_{\mathrm{F}}=$ shear zone thickness at experiment end. $\mathrm{d}_{\mathrm{ax}}=$ axial displacement of the load piston. $\mathrm{d}$ ) Schematic stressdisplacement curves of experiments showing hardening and weakening behaviour. The term 'sample loading' refers to the initial part of the stress-displacement curve before the point of highest curvature (black vertical arrow) is reached. For all but one sample, the point of highest curvature coincides with peak stress.

Table 1

List of experiments and experimental conditions.

\begin{tabular}{|c|c|c|c|c|c|c|c|c|c|c|}
\hline $\begin{array}{l}\text { Experiment } \\
\text { Number }\end{array}$ & & $\begin{array}{l}\mathrm{T} \\
{\left[{ }^{\circ} \mathrm{C}\right]}\end{array}$ & $\begin{array}{l}\mathrm{Pc}[\mathrm{MPa}] \\
\text { at peak }\end{array}$ & $\begin{array}{l}\text { Pc }[\mathrm{MPa}] \\
\text { at end }\end{array}$ & $\begin{array}{l}\text { peak } \tau \\
{[\mathrm{MPa}]}\end{array}$ & $\begin{array}{l}\text { average } \tau \text { at } \\
\text { flow }[\mathrm{MPa}]\end{array}$ & $\begin{array}{l}\text { SZ thickness at } \\
\text { start }[\mathrm{mm}]\end{array}$ & $\begin{array}{l}\text { SZ thickness at } \\
\text { end }[\mathrm{mm}]\end{array}$ & $\begin{array}{l}\text { axial displacement } \\
{[\mathrm{mm}] \text { from hit point }}\end{array}$ & $\begin{array}{l}\text { axial displacement } \\
\text { rate }^{\mathrm{b}}[\mathrm{m} / \mathrm{s}]\end{array}$ \\
\hline 367 & & 600 & 566 & 587 & 620 & 455 & 0.82 & 0.64 & 1.31 & 2.1E-08 \\
\hline 369 & & 500 & 526 & 565 & 738 & 680 & 0.82 & 0.65 & 1.44 & $2.0 \mathrm{E}-08$ \\
\hline 373 & & 600 & 518 & 548 & 614 & 469 & 0.82 & 0.67 & 1.71 & $1.9 \mathrm{E}-08$ \\
\hline 374 & & 300 & 553 & 571 & 1101 & 1012 & 0.82 & 0.68 & 1.60 & $1.9 \mathrm{E}-07$ \\
\hline 375 & & 300 & 538 & 565 & 1022 & 954 & 0.82 & 0.71 & 1.56 & $2.0 \mathrm{E}-08$ \\
\hline 395 & & 300 & 1000 & 1038 & 1318 & 1059 & 0.82 & 0.60 & 1.72 & $2.2 \mathrm{E}-08$ \\
\hline 397 & & 500 & 993 & 1033 & 1051 & 890 & 0.82 & 0.62 & 1.59 & $1.9 \mathrm{E}-08$ \\
\hline 399 & & 600 & 999 & 1045 & 930 & 752 & 0.82 & 0.62 & 1.85 & $2.0 \mathrm{E}-08$ \\
\hline 401 & 1) & 500 & 1012 & na & 928 & na & 0.82 & 0.75 & 0.50 & 7.1E-09 \\
\hline 402 & 2) & 500 & na & na & na & na & 0.82 & 0.82 & 0.00 & - \\
\hline 418 & & 300 & 536 & 568 & 978 & 894 & 0.82 & 0.60 & 2.04 & $1.9 \mathrm{E}-08$ \\
\hline 421 & 1) & 300 & 517 & na & 973 & na & 0.82 & 0.72 & 0.97 & $9.5 \mathrm{E}-09$ \\
\hline 442 & 3) & 300 & & & & 877 & \multirow[t]{2}{*}{0.82} & \multirow[b]{2}{*}{0.59} & & 1.9E-08 \\
\hline & & & 554 & 564 & 963 & 961 & & & $2.28^{\mathrm{a}}$ & 1.6E-07 \\
\hline 444 & 3) & 300 & 528 & & 937 & 869 & \multicolumn{3}{|l|}{0.82} & $1.7 \mathrm{E}-08$ \\
\hline & & & & 571 & & 765 & & \multicolumn{2}{|r|}{$1.77^{\mathrm{a}}$} & 2.0E-09 \\
\hline 483 & & 500 & 530 & 570 & 792 & 665 & 0.82 & 0.64 & 1.83 & $2.0 \mathrm{E}-08$ \\
\hline 501 & & 600 & 1010 & 1054 & 903 & 688 & 0.82 & 0.57 & 1.86 & $2.4 \mathrm{E}-08$ \\
\hline 509 & & 300 & 545 & 576 & 1069 & 957 & 0.82 & na & 1.72 & 2.2E-08 \\
\hline 521 & & 300 & 544 & 562 & 1065 & 935 & 0.82 & na & 1.38 & $2.2 \mathrm{E}-08$ \\
\hline $\begin{array}{l}\text { Experiment } \\
\text { Number }\end{array}$ & $\begin{array}{l}\mathrm{T} \\
{\left[{ }^{\circ} \mathrm{C}\right]}\end{array}$ & & $\begin{array}{l}\mathrm{Pc}[\mathrm{MPa}] \text { at } \\
\text { peak }\end{array}$ & $\begin{array}{l}\mathrm{Pc}[\mathrm{MPa}] \text { at } \\
\text { end }\end{array}$ & $\begin{array}{l}\Delta \sigma \text { at end } \\
{[\mathrm{MPa}]}\end{array}$ & $\begin{array}{l}\text { sample len } \\
\text { start }[\mathrm{mm}\end{array}$ & $\begin{array}{l}\text { sample } \\
\text { end }[\mathrm{mr}\end{array}$ & $\begin{array}{l}\text { axial } \\
\text { from }\end{array}$ & $\begin{array}{l}\text { splacement }[\mathrm{mm}] \\
\text { t point }\end{array}$ & $\begin{array}{l}\text { axial displacement } \\
\operatorname{rate}^{\mathrm{b}}[\mathrm{m} / \mathrm{s}]\end{array}$ \\
\hline 475 & 300 & & - & 636 & 1846 & 15.80 & 12.7 & 3.33 & & 8.3E-09 \\
\hline
\end{tabular}

1) experiment terminated at peak stress.

2) experiment terminated at hit-point.

3) displacement rate stepping test.

na $=$ no data available.

a Total displacement from start to end of experiment.

${ }^{\mathrm{b}}$ Average displacement rate.

implying any specific deformation mechanism or deformation regime.

The term "fault network" or "fault zone" is used to refer to zones of localized accommodation of displacement along segments of shear bands, shear fractures or a combination of both. The term is used without implying any specific deformation mechanism or deformation regime.

\section{Results}

\subsection{Mechanical data, general shear experiments}

At all imposed Pc-T (and displacement rate) conditions, samples show initial loading to a peak differential stress and subsequent weakening, which is often followed by a more constant stress value with increasing displacement (Fig. 2a and b). Sample strengths are observed 


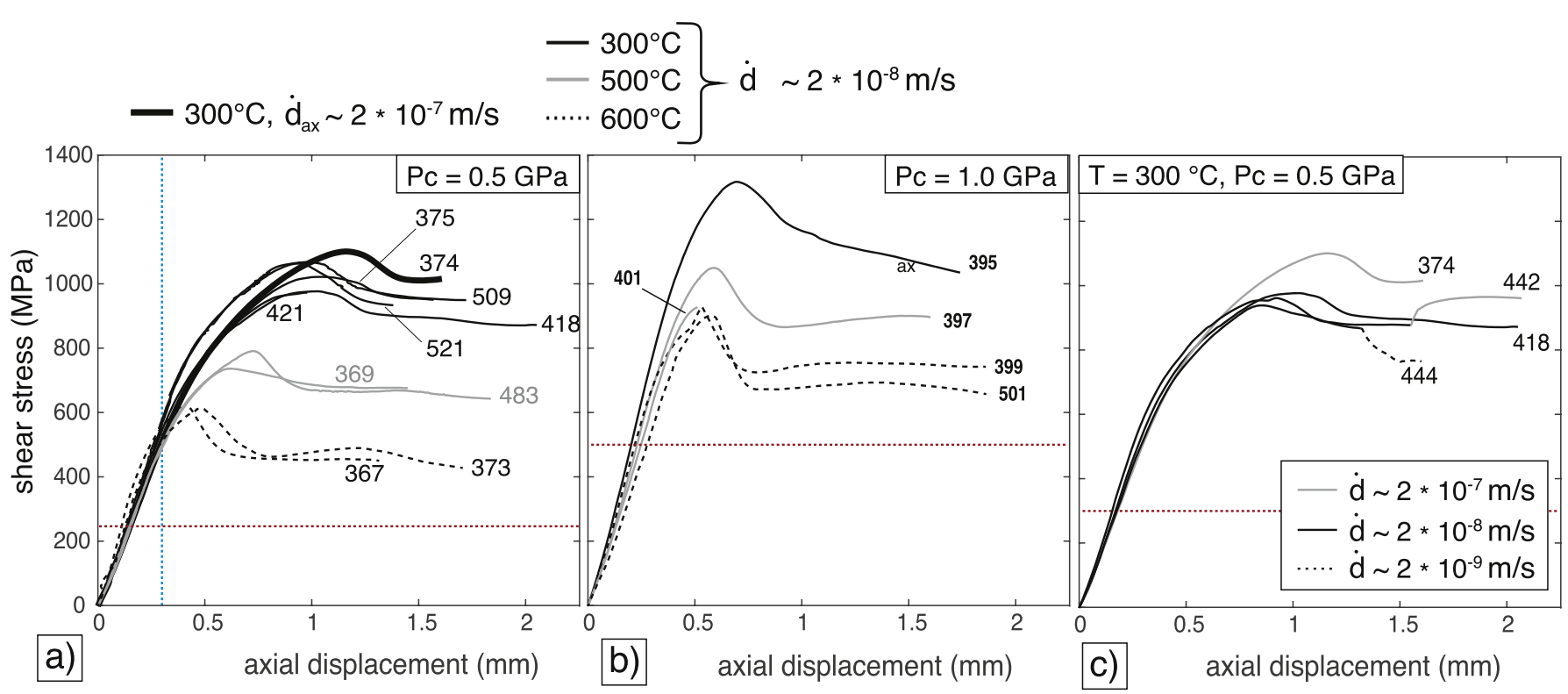

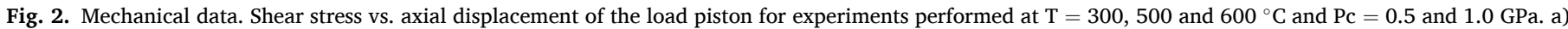

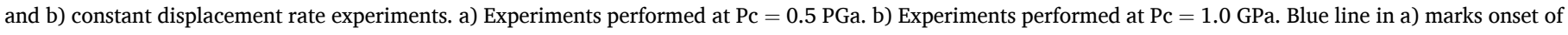

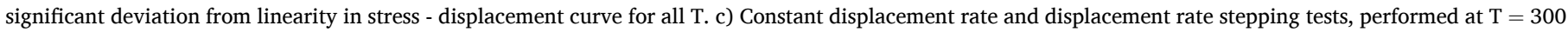

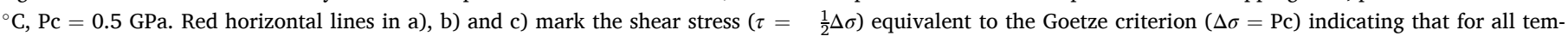
peratures $\Delta \sigma>$ Pc. (For interpretation of the references to colour in this figure legend, the reader is referred to the Web version of this article.)

to depend on both temperature and pressure. The pressure dependence of strength is positive, i.e., samples become stronger with increasing confining pressures. The temperature dependence is negative, i.e., samples are weaker at higher temperatures. Sample strengths always remain above the Goetze criterion, which defines the differential stress above which plastic deformation is usually observed to grade into brittle or semi-brittle deformation as $\Delta \sigma \leq \mathrm{P}_{\text {conf }}$ (Kohlstedt et al., 1995). Thus, all samples are expected to show semi-brittle or brittle deformation.

Significant amounts of permanent strain are accommodated in all experiments and although samples show weakening after peak stress, none experienced abrupt failure or dramatic loss of shear resistance. Peak stresses in experiments performed at different temperatures are reached after different amounts of displacement. The higher the experimental $\mathrm{T}$, the earlier the peak stress is reached in terms of displacement (Fig. 2). This effect is more pronounced at the lower Pc of 0.5 GPa than at 1.0 GPa (Fig. 2a and b). At Pc $\approx 0.5 \mathrm{GPa}$, the initial parts of the loading curve are similar for the different experiments and are approximately linear (for axial displacements $\leq 0.3 \mathrm{~mm}$, Fig. 2a).

In displacement rate stepping tests, at $\mathrm{T}=300^{\circ} \mathrm{C}$ and $\mathrm{Pc} \approx 0.5 \mathrm{GPa}$, at rates of $\sim 2 \cdot 10^{-8}$ to $2 \cdot 10^{-9} \mathrm{~ms}^{-1}$, and $\sim 2 \cdot 10^{-8}$ to $2 \cdot 10^{-7} \mathrm{~ms}^{-1}$, sample strength is weakly sensitive to the imposed displacement rate (Fig. 2c), and stress exponents (n) calculated from the data are on the order of $\mathrm{n} \approx 21$ (Marti et al., 2017). Using stress exponent values published in Marti et al. (2017), activation energy (Q) estimates have been obtained for experiments at $\mathrm{Pc}=0.5 \mathrm{GPa}$. We followed the procedure described in Twiss and Moores (2007, p. 486), Q-values for deformation between 300 and $500{ }^{\circ} \mathrm{C}$ are markedly lower, with $\sim 130 \mathrm{~kJ} / \mathrm{mol}$, than between 500 and $600{ }^{\circ} \mathrm{C}$, with $\sim 380 \mathrm{~kJ} / \mathrm{mol}$. The results suggest that the temperature sensitivity of the deformation process increases with higher experimental temperature (Appendix Fig. 2).

\subsection{Microstructural overview - general shear experiments}

The deformed samples show pervasive and intense grain size reduction by fracturing. A foliation, defined by elongated mineral aggregates, is formed due to cataclastic flow (Fig. 3). Both, plagioclase and pyroxene, are pervasively fractured. However, pyroxene grains tend to show longer through-going fractures and larger non-fractured domains, whereas plagioclase tends to be pervasively fractured into fine fragments (Fig. 3c).

In all samples, strain localizes into a fault network, composed of segments of shear bands and shear fractures. Usually, two to three larger fault zones crosscut the sample, transferring displacement from one end of the sample to the other (Fig. 4). For experiments at $300{ }^{\circ} \mathrm{C}$, the relative volume of shear bands is seen to increase with increasing bulk displacement, from $\sim 2.0$ area- $\%$ in sample 375 (1.56 $\mathrm{mm}$ axial displacement) to $\sim 3.4$ area- $\%$ in sample $418(2.04 \mathrm{~mm}$ axial displacement).

Although strain mainly localizes within the fault network, the "low strain" lenses in-between accommodate some of the strain, as seen from the foliation formation as a result of cataclastic flow (Fig. 3b and c). At the end of an experiment, the sample material is cohesive, as could be observed from samples cut in half without previous epoxy impregnation.

\subsection{Shear band microstructure}

Shear bands consist either of ultra-cataclasites (referred to as type I shear bands) or of a material that appears homogeneous without resolvable grain boundaries or clear grain fragments (at SEM resolution) - in the following referred to as type II shear bands. Type II shear bands form along the localized large strain fault networks that crosscut the sample, as well as along the forcing block and sample interface (Fig. 4). The shear bands are recognized by a clear foliation deflection, where the foliation within the shear bands is defined by a nano-to micrometer scale compositional layering (Fig. 5). The shear bands consist of a cohesive, non-porous material, with only few grains resolvable in the SEM (Fig. 5 b, d), and with the compositional layering either laminar or perturbed in flow structures (Fig. 5b, d). From their homogeneous appearance (as seen in the SEM) without any resolvable grains, the material of type II shear bands is presumed to be of nano-crystalline or amorphous nature. Usually no syn-kinematic fracture porosity (at SEM resolution) can be found within type II shear bands. This is in contrast to the surrounding host material (Fig. 5b-d), which is pervasively fractured (syn-kinematic fractures) with a relatively abrupt transition from the fractured host to the homogeneous matrix of the shear band (Fig. 5b and c). Unloading 

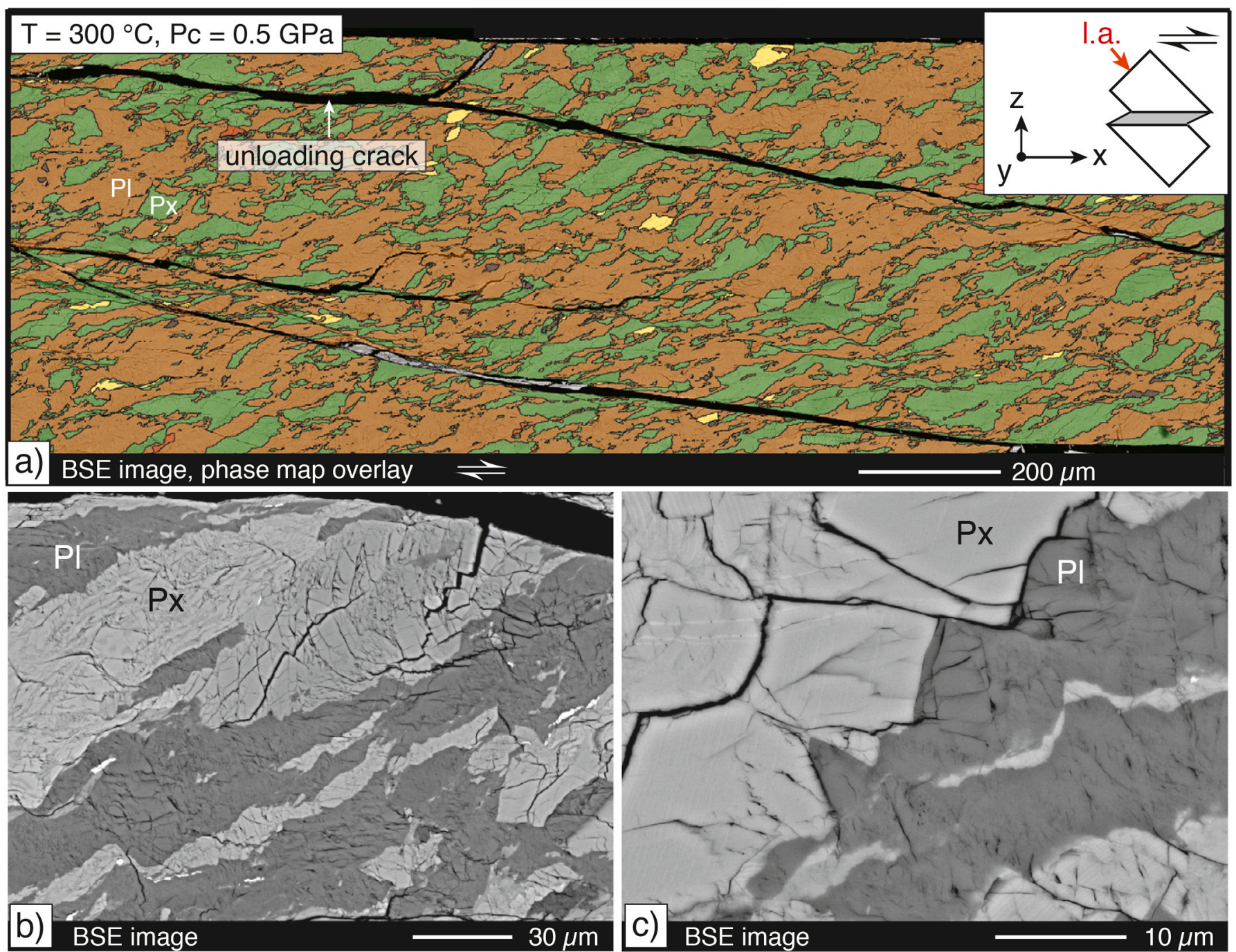

Fig. 3. Microstructures of cataclastic flow. a) Central part of sample 375 , deformed at $\mathrm{T}=300{ }^{\circ} \mathrm{C}, \mathrm{Pc}=0.5 \mathrm{GPa}$. Digital phase map overlay on BSE SEM image. Orange: plagioclase (Pl), green: pyroxene (Px), yellow: oxides, red: apatite, dark grey: quartz. Sketch in upper right indicates kinematic reference frame. 1.a. $=$ load axis (parallel to axial displacement direction). b) Foliation defined by elongated aggregates of intensely fractured grains. c) Grain size reduction by fracturing down to sub-micron size fragments. Plagioclase typically shows more intense fragmentation than pyroxene. (For interpretation of the references to colour in this figure legend, the reader is referred to the Web version of this article.)

cracks (formed after the experiment, during de-pressurization) are localized within the type II shear bands (Fig. 5d) indicating different physical behavior of the shear bands and the adjacent wall rock material (similar observations were made by, e.g., Stünitz et al., 2003).

Type II shear bands are found in experiments at all three tested temperatures but are most common in $300{ }^{\circ} \mathrm{C}$ experiments and especially at the lower Pc of $0.5 \mathrm{GPa}$. The shear bands show variable thickness, mostly between $\sim 2$ and $20 \mu \mathrm{m}$. In $300{ }^{\circ} \mathrm{C}$ experiments, they appear to become wider with increasing bulk displacement imposed on the sample. This behaviour is not so obvious in the higher T samples at 500 and $600{ }^{\circ} \mathrm{C}$.

The ultra-cataclastic type I shear bands are usually narrow $(<10 \mu \mathrm{m}$ in width) and contain sub-micron sized, angular grains (Fig. 6a and b). Wider $(20 \mu \mathrm{m})$ cataclastic type I shear bands are found at $600{ }^{\circ} \mathrm{C}$ and Pc $\approx 0.5 \mathrm{GPa}$, with relatively rounded grains and a wide range of grain sizes (Fig. $6 \mathrm{c}$ and d). The rounded grains show evidence of dissolution and pore trails are ubiquitous (Fig. 6e), indicating fluid presence and partial fault healing.

While type II shear bands are most frequent (for the same amount of total displacement) in $300{ }^{\circ} \mathrm{C}$ experiments, the cataclastic type $I$ shear bands occur more commonly at 500 and especially $600{ }^{\circ} \mathrm{C}$, as well as more commonly in the lower Pc experiments. Shear bands formed at the interface to the forcing block, at all temperatures and confining pressures, are dominantly of type II.

One experiment $\left(\mathrm{T}=300{ }^{\circ} \mathrm{C}, \mathrm{Pc} \approx 0.5 \mathrm{GPa}\right)$ was terminated at peak stress to study the microstructures that form during the 'loading' part of the experiment (Fig. 1d). An incipient, weak foliation caused by cataclastic flow resulting in aggregate elongation is present at the point that the peak stress is reached (Fig. 7). Strain is only weakly localized but some zones of more intense grain size reduction by fracturing are observed, with minor localization of shear displacement within them (Fig. $7 \mathrm{~b}$ and c). The sample shows that only small amounts of displacement are needed to fracture the sample pervasively down to submicron sized fragments (sample 421, terminated at peak stress after an axial displacement of $\sim 1 \mathrm{~mm}$ ).

\subsubsection{Shear band structures observed in TEM}

Type II shear bands formed in general shear experiments $418(\mathrm{~T}=$ $\left.300{ }^{\circ} \mathrm{C}, \mathrm{Pc}=0.5 \mathrm{GPa}\right)$ and $373\left(\mathrm{~T}=600^{\circ} \mathrm{C}, \mathrm{Pc}=1.0 \mathrm{GPa}\right)$ were studied in more detail using the TEM. The analyzed shear bands from both samples are composed of nano-crystalline and amorphous material in lenses and layers (Fig. 8). The amorphous nature can be confirmed by (i) 

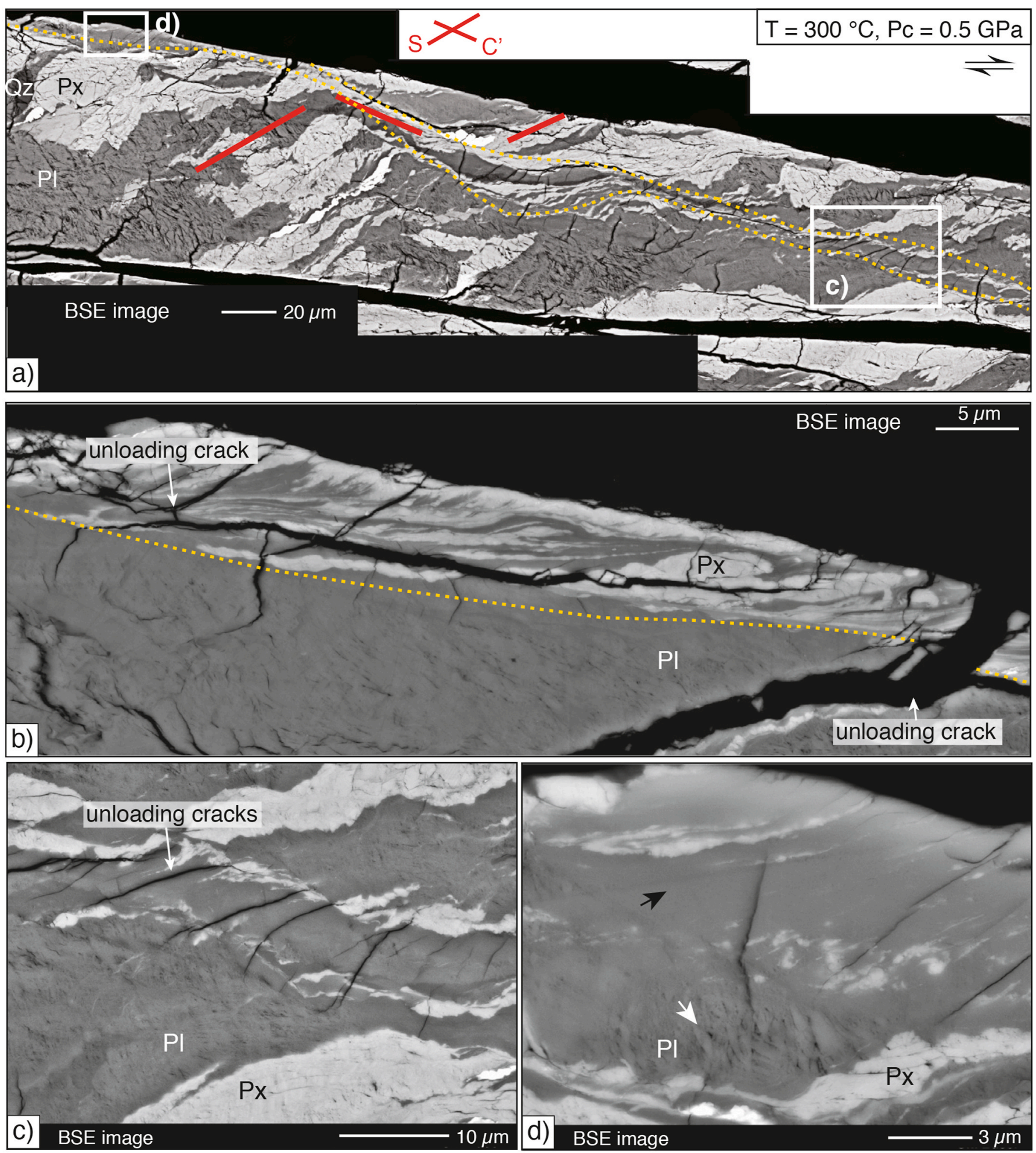

Fig. 5. Microstructure of type II shear bands. a) Shear band (outlined by dotted orange lines) crosscutting the sample in Riedel R1 orientation. Foliation in the adjacent wall-rock is deflected into a foliation sub-parallel to the shear band boundaries which is defined by a fine-scale compositional layering. Red lines indicate foliation traces. b) The compositional layering in type II shear bands (boundary traced with dotted orange line) can be laminar or perturbed leading to flow structures. c) Close-up of area marked in a). Unloading cracks preferentially form within the shear band material. c) and d) A sharp transition between intensely fractured host and shear bands is clearly recognizeable. White arrow in d) points to residual porosity in fractured/crystalline wall rock material next to the shear band, black arrow to homogeneous appearing shear band without any resolvable grains or porosity. (For interpretation of the references to colour in this figure legend, the reader is referred to the Web version of this article.) 

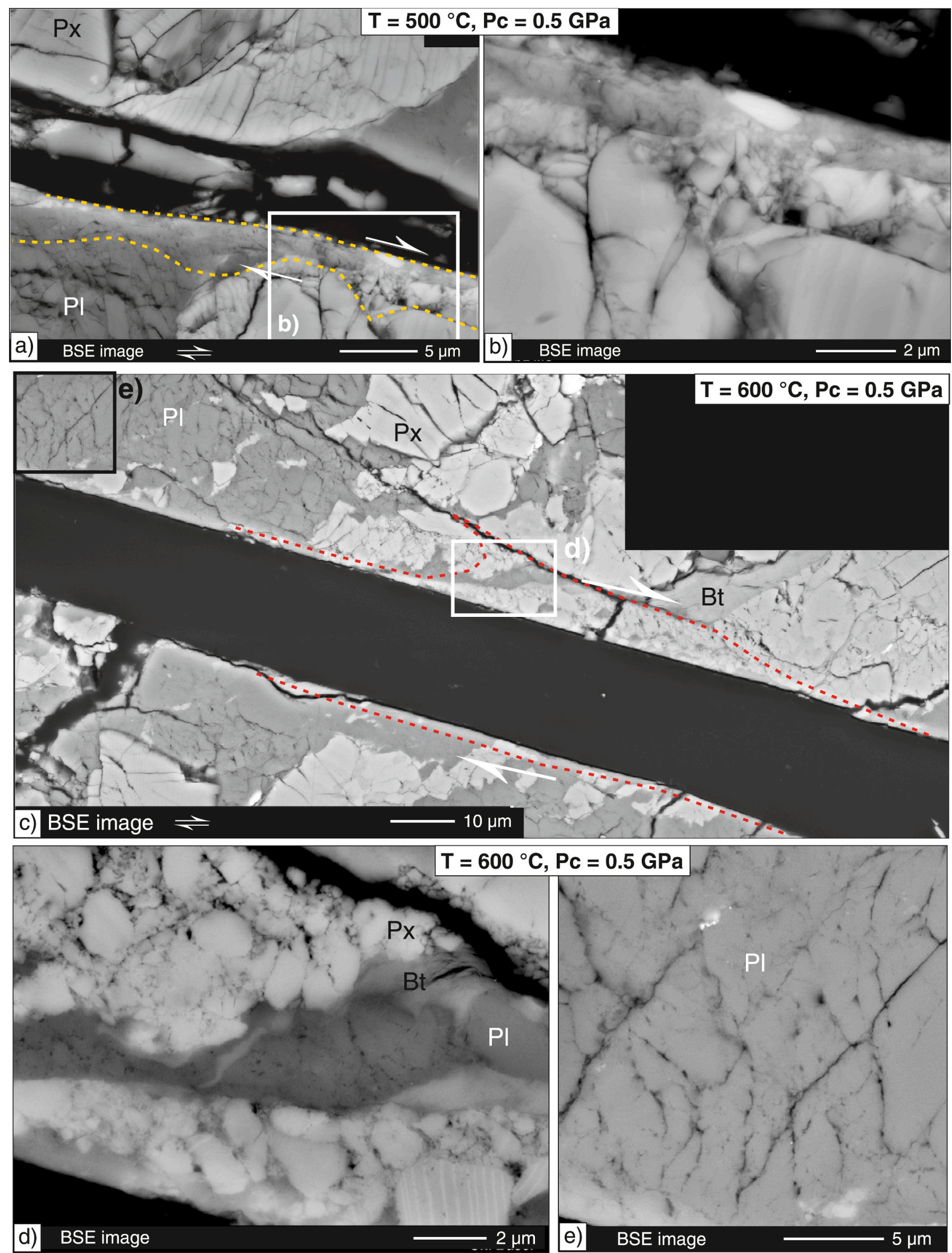
Fig. 6. Microstructure of type I shear bands. a) Displacement is accommodated by a narrow ( $\sim 2 \mu \mathrm{m}$ wide) ultra-cataclastic zone (outlined by orange dotted line). Sample 369 , deformed at $500^{\circ} \mathrm{C}, 0.5 \mathrm{GPa}$ Pc). b) Close-up of area marked in a). The ultra-cataclastic zone consists of sub-micron sized angular fragments. c) Sample 373. Unique cataclastic shear bands (traced with red dotted lines) only formed in $600{ }^{\circ} \mathrm{C}, 0.5 \mathrm{GPa}$ experiments. Shear band is composed of rounded grains with a broad size distribution. Black = unloading crack. d) Detail of c). e) Partly healed fractures decorated with pore trails, indicating fluid presence. (For interpretation of the references to colour in this figure legend, the reader is referred to the Web version of this article.)

mechanical data.

The thin section of sample 475 was prepared parallel to the compression axis and the dip direction of the major fault marked in red in Fig. 11a. The microstructures found along this fault are very similar to those observed in the general shear experiments: (i) A weak foliation formed in the vicinity of the main fault zones (Fig. 11e-g). (ii) The narrow, 10-20 $\mu \mathrm{m}$ wide main fault shows deflection of the foliation and (iii) the main shear band shows a shear-band-parallel compositional banding with flow structures, no resolvable syn-kinematic porosity or clasts, and an accumulation of unloading cracks (compare e.g. with Fig. 5).

The influence of sample geometry $\left(45^{\circ}\right.$ pre-cut vs. whole rock cylinder) on fault network formation is investigated by means of comparing angles of fractures and shear band traces with respect to the loading direction. For this, the major fault in the axial shortening experiment
475 (Fig. 11a), and the fault network in two general shear experiments (375 and 418, Fig. 4) were analyzed (details in Appendix A3). The general shear experiments differ in total amount of axial displacement $\left(d_{a x}\right)$, with $1.56 \mathrm{~mm}$ for sample 375 and $2.05 \mathrm{~mm}$ for sample 418 , while sample 475 attains a maximum $d_{a x}$ value of $3.33 \mathrm{~mm}$.

Given that the dominant mode of failure is brittle, faults are expected to form with angles $\theta$ of approximately $30^{\circ}$ to the load axis unless geometrically constrained to another orientation. The axial shortening experiment, sample 475 , shows that $79 \%$ of all measured fault segments fall within a range of angles of $20^{\circ} \leq \theta \leq 40^{\circ}$ (Fig. 12a), with the shorter $(<0.3 \mathrm{~mm})$ fault segments displaying a wider scatter of $5^{\circ} \leq \theta \leq 45^{\circ}$. In the general shear experiments, for $\mathrm{d}_{\mathrm{ax}}=1.57 \mathrm{~mm}$ (sample 375 , Figs. $12 \mathrm{~b}$ ), $85 \%$ of the fault segments are inclined with $20^{\circ} \leq \theta \leq 40^{\circ}$ from the load axis and thus are not parallel to the $45^{\circ}$ forcing block boundaries. With increasing displacement, $\mathrm{d}_{\mathrm{ax}}=2.05 \mathrm{~mm}$ (sample 418,
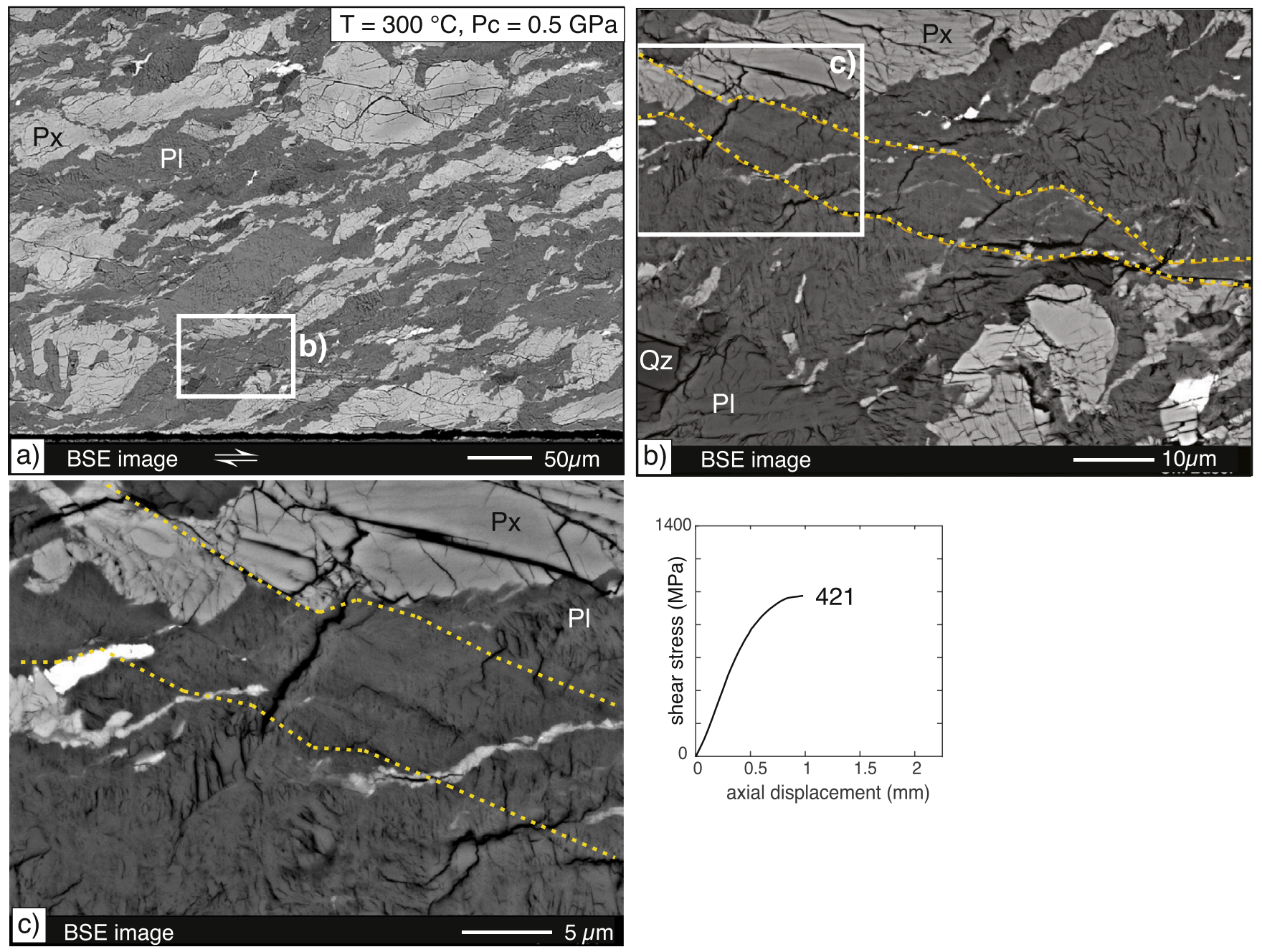

Fig. 7. Shear localization at peak stress. a) Overview of experiment $421\left(300{ }^{\circ} \mathrm{C}, 0.5 \mathrm{GPa}\right)$, terminated at peak stress (see stress displacement curve in lower right). Deformation is mainly accommodated by distributed cataclastic flow but zones of strain localization can already be recognized. b) Close-up of area marked in a). Ultra-cataclastic zone (traced in orange) with more intense grain size reduction by fracturing. Strain localization is shown by the weak deflection of small Px aggregates. c) Close-up of area marked in b). The ultra-cataclasite is outlined by orange dotted lines and shows a slightly stronger grain size refinement by more intense fracturing. (For interpretation of the references to colour in this figure legend, the reader is referred to the Web version of this article.) 

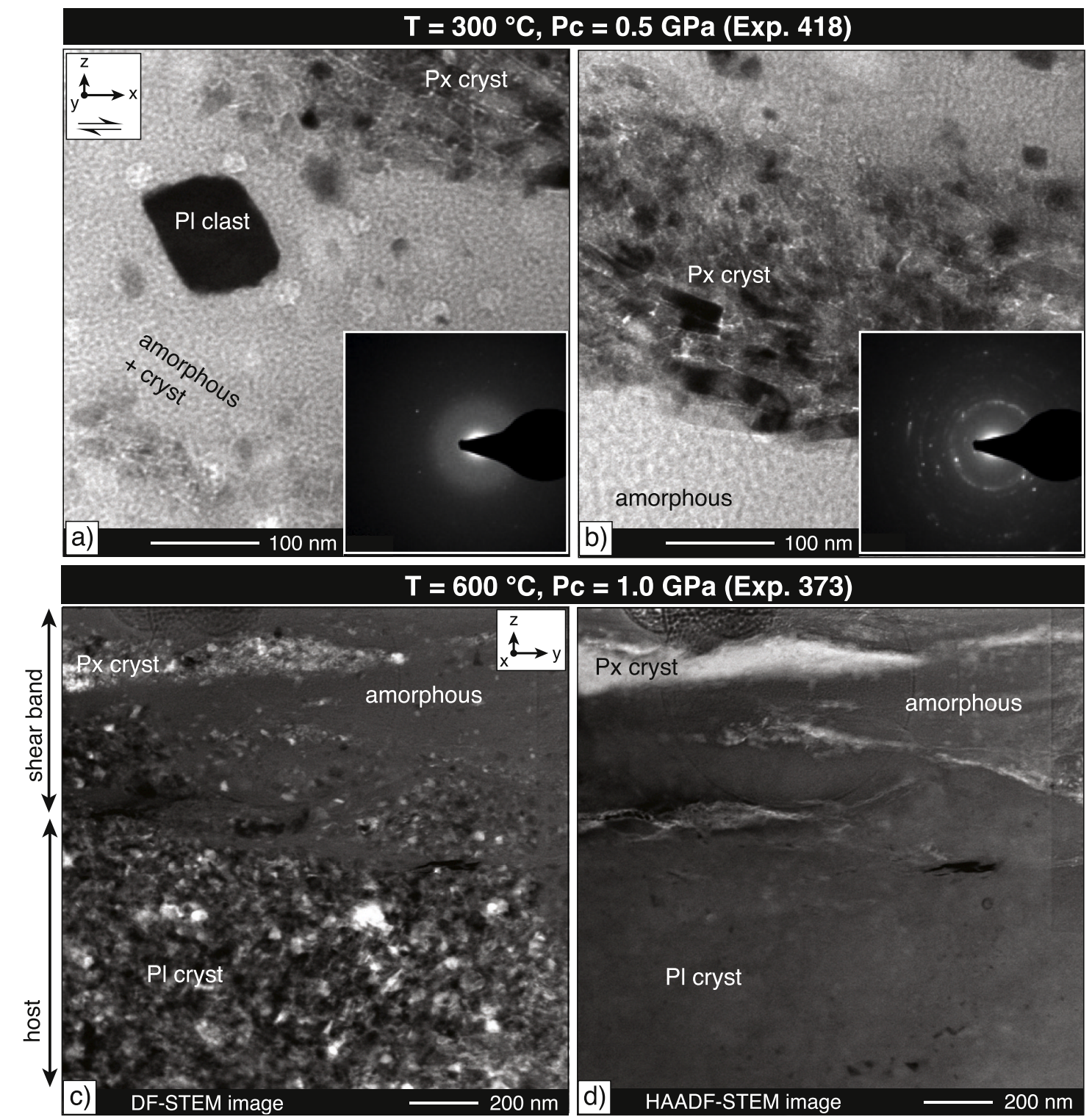

$P_{c}=1.0 \mathrm{GPa}$ (Exp. 373)
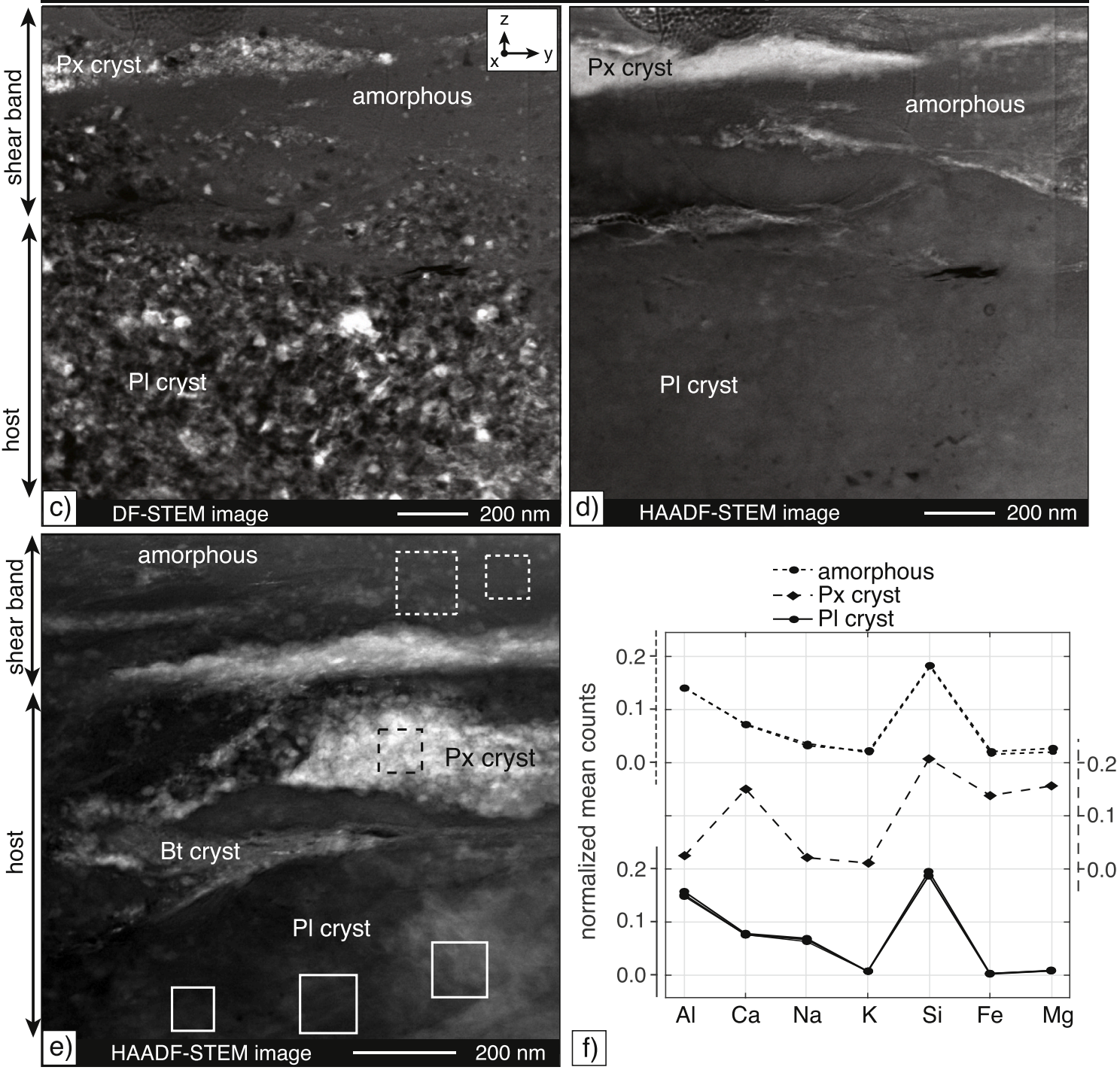


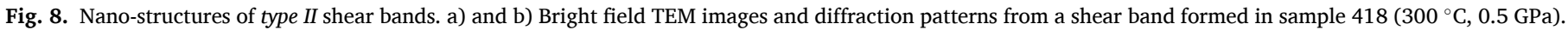

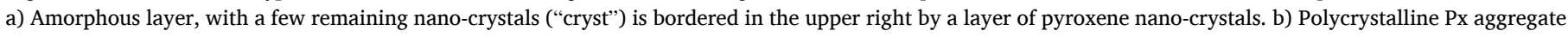

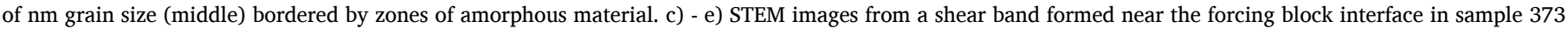

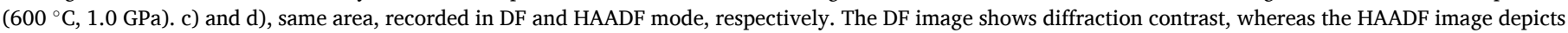

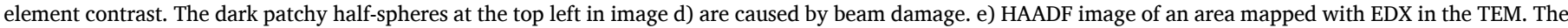

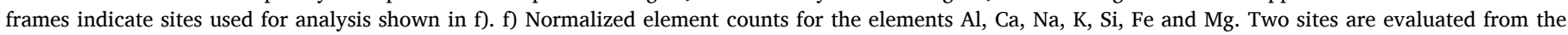
amorphous part of the shear band, one from a nano-crystalline Px aggregate and three individual sites from a Pl aggregate. cryst $=$ crystalline.

Fig. 12c), faults with angles $\theta>40^{\circ}$ become more frequent, while $66 \%$ of all measured fault segments remain within $20^{\circ} \leq \theta \leq 40^{\circ}$. The frequency distributions of fault angles for the different experiments all show similar modes in the range of $32-34^{\circ}$. The distributions, however, vary, displaying a narrow, symmetric distribution for sample 375 and a broader distribution for the larger displacement experiment 418. The axial shortening experiment shows a narrow range of high frequency bins with some low-frequency bins broadening the distribution.

\section{Discussion}

Semi-brittle deformation of our samples accommodates significant amounts of displacement without leading to an abrupt stress drop (Fig. 2). At all temperatures, the mechanical data and microstructures indicate cataclastic/semi-brittle deformation causing intense grain size reduction and the formation of a weak foliation by cataclastic flow. Whereas cataclastic flow occurs pervasively throughout the samples, the major part of the displacement localizes into a fault network of thin shear bands and shear fractures (e.g. Figs. 4 and 10), beginning at around peak stress conditions (axial displacements $\approx 0.5-1 \mathrm{~mm}$ ).

In accordance with the widespread signs of brittle deformation in the microstructure, the mechanical data shows a positive pressure dependence of strength at all experimental temperatures (Fig. 2a and b). As fracturing is accompanied by dilatancy, work against the confining pressure is required. Hence increasing confining pressure suppresses fracturing (e.g. Paterson and Wong, 2005). Beside the positive pressure dependence typical for brittle deformation, a temperature sensitivity of the samples is observed, with significantly lower strengths at higher experimental temperatures. This behavior is typically associated with temperature-activated viscous processes and demonstrates semi-brittle behavior for the samples having a bulk mechanical response with characteristics of both brittle and viscous deformation. This mixed mechanical response can be explained as the result of different sample domains deforming with different dominant modes of deformation.

The brittle structures such as pervasive fracturing and cataclasis are clear in the microstructure. However, the cause of the viscous response is less obvious. Based on microstructural observations, two causes for the temperature dependence of strength are proposed: (i) Dissolutionprecipitation creep is indicated at $600{ }^{\circ} \mathrm{C}$ by the presence of rounded grains and the absence of sharp corners in clasts (Fig. 6d). Pore trails along partially healed fractures (Fig. 6e) indicate the presence of fluids and solution transfer of material. (ii) Partly amorphous shear bands form in all experiments. They accommodate large amounts of displacement and exhibit flow structures indicative of viscous flow.

\subsection{The cause of temperature sensitive sample strength}

Diffusion creep by dissolution-precipitation is indicated at the highest experimental $\mathrm{T}$ of $600{ }^{\circ} \mathrm{C}$, from fracture healing and highly rounded corners of clasts (Fig. $6 \mathrm{~d}$ and e). At this experimental T, it is likely that part of the temperature-sensitivity of strength is due to strain accommodation by dissolution-precipitation creep. However, the $\mathrm{T}$ dependence of strength is observed for all experimental T between 300 and $600{ }^{\circ} \mathrm{C}$, whereas no indications for dissolution-precipitation creep are observed in the microstructure at $\mathrm{T} \leq 500{ }^{\circ} \mathrm{C}$. Dissolutionprecipitation creep thus cannot fully explain the decreasing sample strength with increasing experimental temperature.

Based on microstructural observations, the amorphous material within shear bands is the weakest material in the samples as it accommodates the largest amount of displacement. The viscosity of the amorphous material decreases with increasing temperature, which suggests that the amorphous material may be responsible for the temperature sensitive behavior recorded in the mechanical data (Fig. 2a and b). Flow structures within the shear bands at all experimental temperatures (Fig. 5b-d) suggest a fluid-like behavior, confirming a continuous temperature-sensitivity of sample strengths in the temperature range of $300-600{ }^{\circ} \mathrm{C}$. Although less obvious from the microstructure, the nanometer-sized fragments bordering shear bands (e.g., Fig. 8c) might accommodate strain via diffusion creep (e.g. Verbene et al., 2019 and references therein), contributing to the temperature-sensitive component of deformation.

In general we see a higher amount of shear bands in low temperature samples (high stress samples) and a low amount of shear bands in high temperature samples (low strength samples). That is, samples at $600{ }^{\circ} \mathrm{C}$ show much higher strain localization than the $300{ }^{\circ} \mathrm{C}$ experiments. Generally in all experiments, a largely amorphous shear band forms at the forcing block-sample interface. In the $600{ }^{\circ} \mathrm{C}$ experiments, this boundary shear is localizing strain much more than in lower $\mathrm{T}$ experiments. We think this can be explained by the increasingly lower viscosity of amorphous shear bands with higher $\mathrm{T}$. Whereas the shear bands are still "strong" enough to support high amounts of bulk sample stress at $300{ }^{\circ} \mathrm{C}$, the shear bands are so weak at $600{ }^{\circ} \mathrm{C}$ that they localize strain much more efficiently. As strain is more localized in the $600{ }^{\circ} \mathrm{C}$ experiments, consequently the low strain lenses show less intense deformation compared to the $300{ }^{\circ} \mathrm{C}$ experiments (e.g., compare Fig. 10a and b).

The activation energy estimates further support the increasing temperature sensitivity of deformation at experimental temperatures of $\geq 500{ }^{\circ} \mathrm{C}$ (Appendix Fig. 2). However, it is emphasized that our samples have deformed in the semi-brittle field and that the Q-values do not represent activation energies that can be used for a quantitative description of plastic deformation. Presented Q-values only serve as a qualitative estimate to demonstrate that the temperature sensitivity of deformation increases with increasing temperature. This is interpreted to show that the dominant deformation process appears to change with increasing temperature, what we attribute to a change in the viscous behavior of the amorphous material.

\subsection{Formation of amorphous material}

Amorphous material is found along fault zones in nature as well as in experiments. Many of these occurrences are attributed to frictional melting during seismic slip (e.g. Philpotts, 1964; Mc Kenzie and Brune, 1972; Sibson, 1975; Spray, 1987; Di Toro et al., 2005; Hirose and Shimamoto, 2005; Del Gaudio et al., 2009; Niemeijer et al., 2011; Hayward et al., 2016). However, amorphous material has also been reported from aseismically creeping faults, both in nature (e.g. Janssen et al., 2010; Kirkpatrick et al., 2013) and experiments (e.g. Yund et al., 1990; Goldsby and Tullis, 2002; Pec et al., 2012, 2016 Hayward et al., 2016). Pec et al. (2012, 2016) and Yund et al. (1990) attribute the formation of amorphous material to mechanical wear and resulting loss of crystallinity from very high defect densities during deformation of their samples. This effect is also observed in ball-milling, e.g., of feldspathic material: (Sanchez et al., 2004). Here we also suggest that the amorphous zones in our samples formed by mechanical wear during deformation and not from frictional melting. In the granitoid samples of Pec et al. (2012, 2016) and Yund et al. (1990), feldspars are seen to readily 

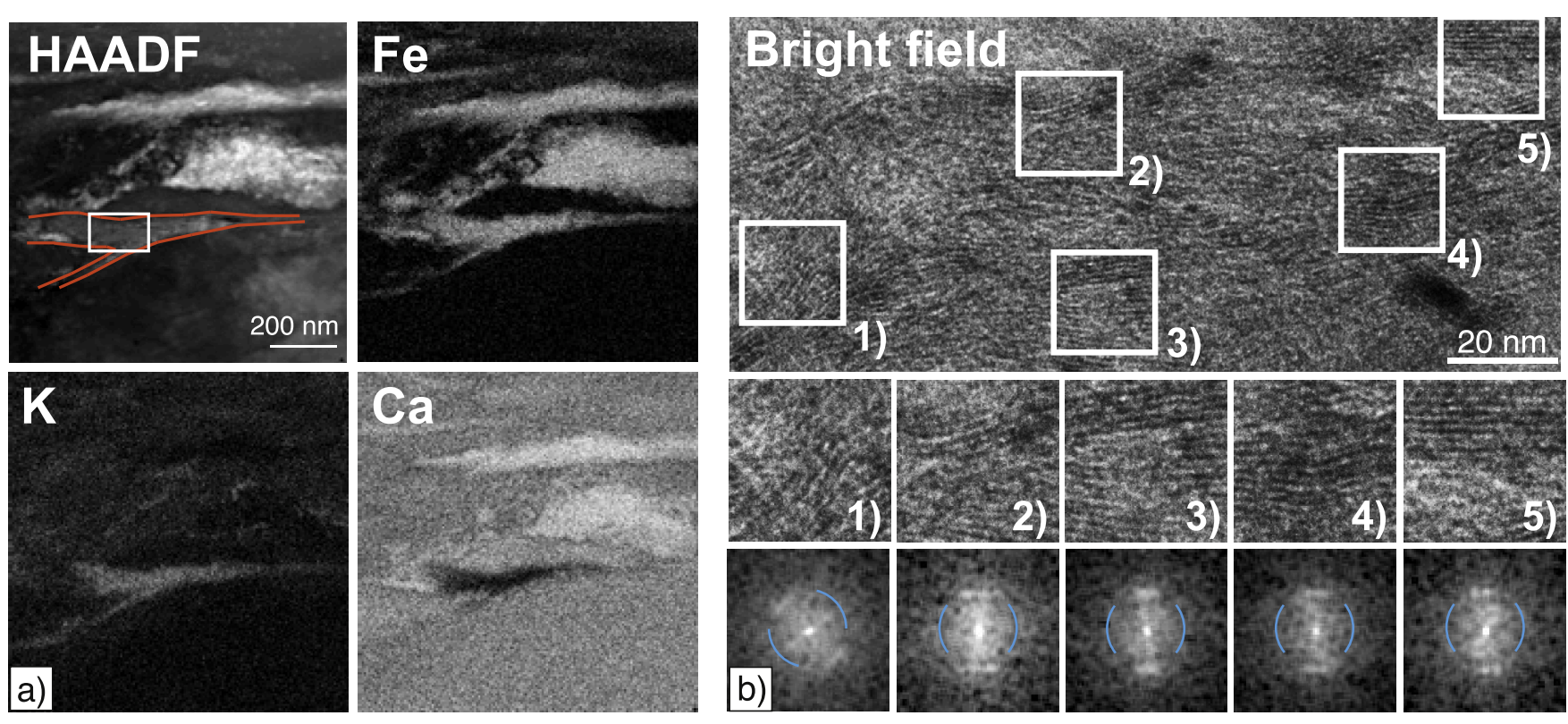

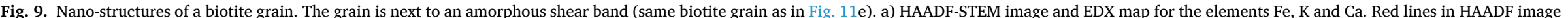

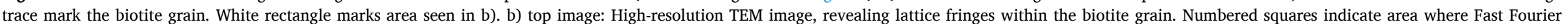

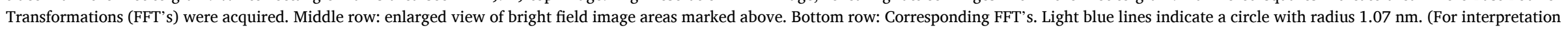
of the references to colour in this figure legend, the reader is referred to the Web version of this article.) 

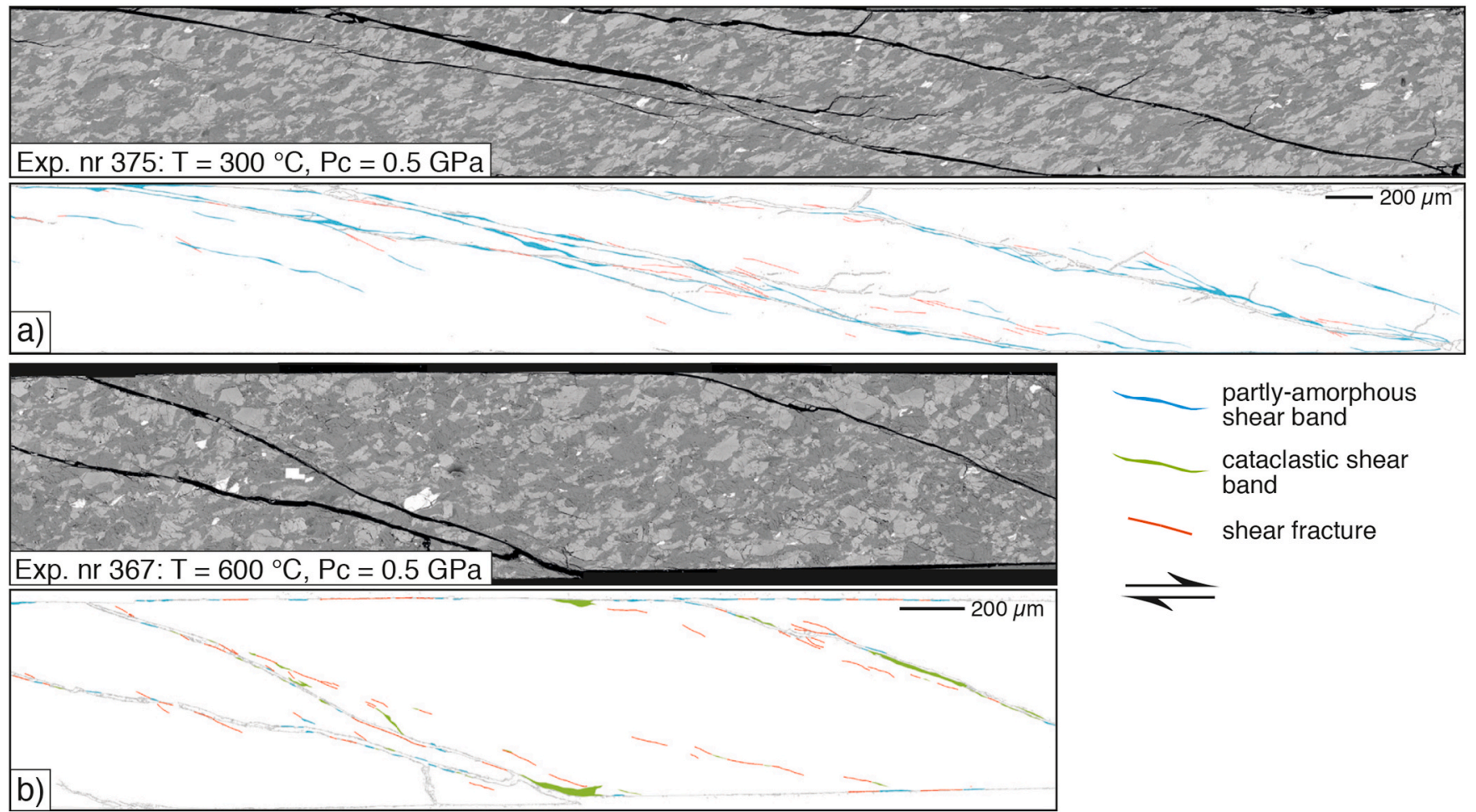

partly-amorphous shear band

cataclastic shear band

shear fracture
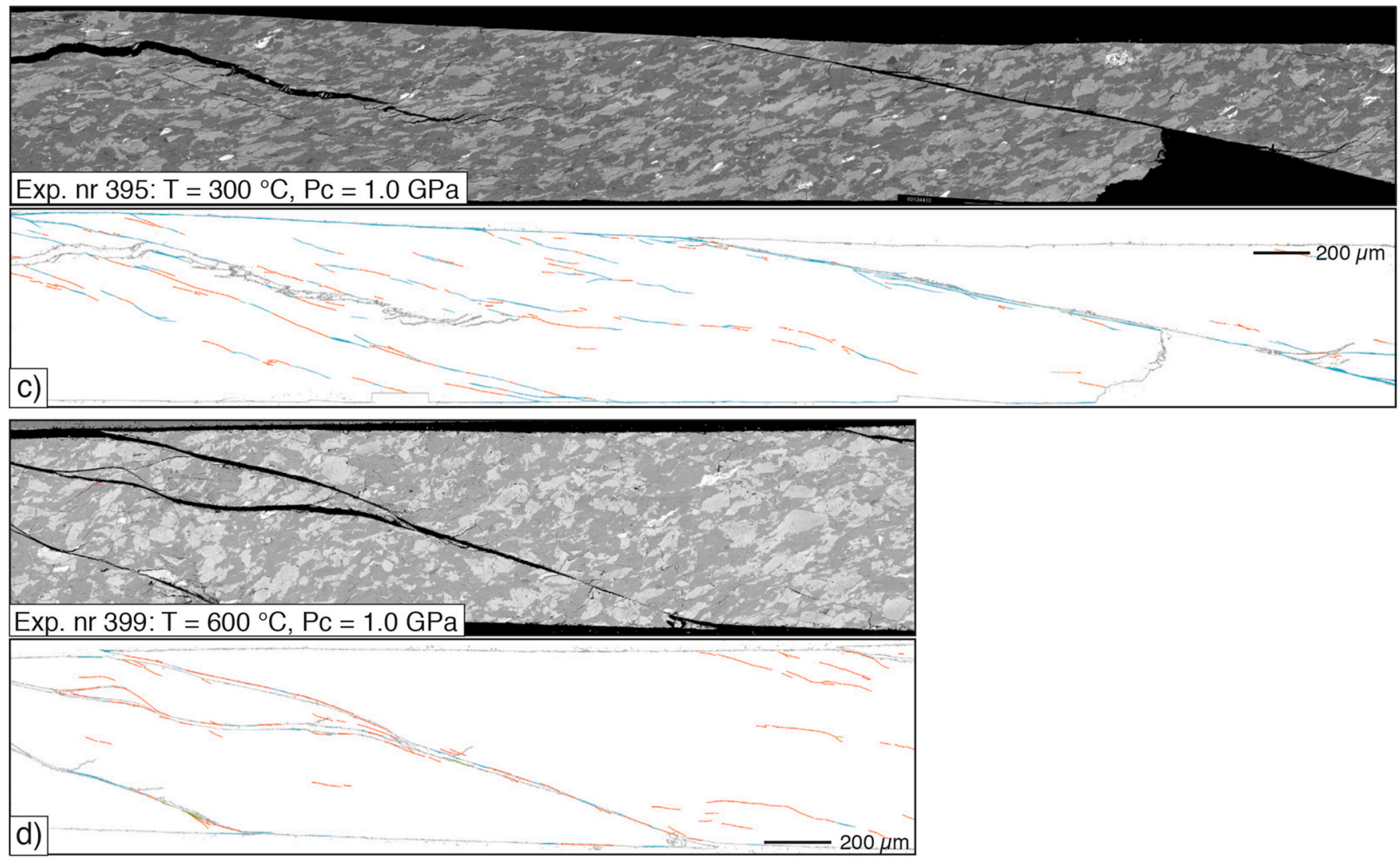

Fig. 10. Microstructural overview of fault zones formed at 300 and $600{ }^{\circ} \mathrm{C}, \mathrm{Pc}=0.5$ and $1.0 \mathrm{GPa}$. BSE images show central parts of each sample. Underneath, the same area is displayed with segmented fault zones.

become amorphous, whereas quartz is often preserved as (nano-)crystalline material. The high susceptibility of plagioclase to amorphisation is supported by our observations, where the chemical composition of the amorphous material is comparable to that of plagioclase (Fig. $8 \mathrm{f}$ ).
Our experiments were performed at displacement rates far from seismic slip rates and melting by frictional heating is unlikely at the low displacement rates. A crush-origin of the amorphous material, i.e. amorphisation by mechanical wear (as opposed to a melt-origin by 


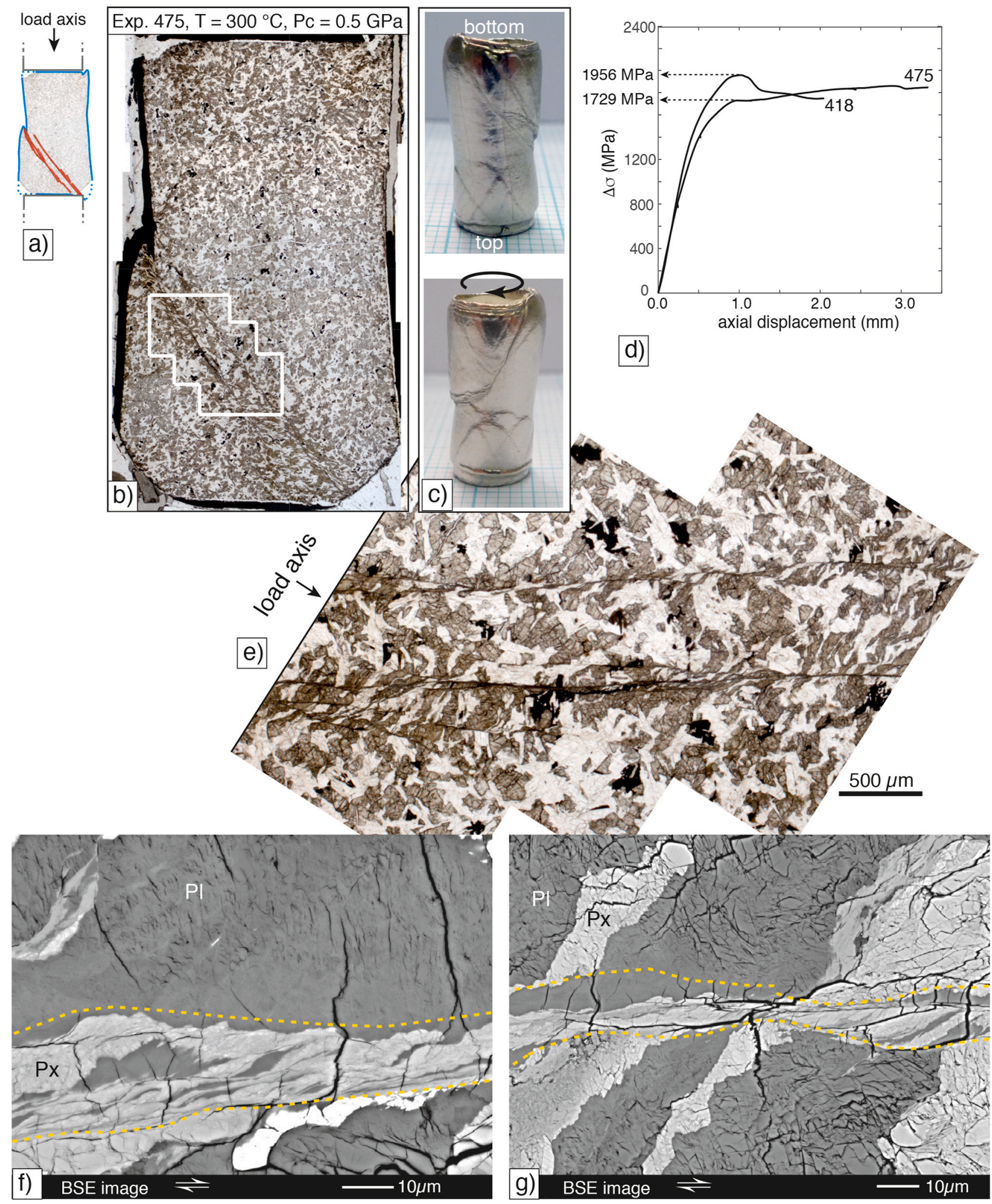

Fig. 11. Axial shortening experiment of Maryland Diabase. a) Sketch of sample with the main fault zones traced in red. b) Thin section scan, plane polarized light. Marked area is shown in e). c) Front and back view of sample after the experiment still sealed in the metal jacket. Conjugated faults crosscut the sample. d) Mechanical data of the axial shortening experiment $475\left(300{ }^{\circ} \mathrm{C}, 0.5 \mathrm{GPa}\right)$ and the general shear experiment 418 for comparison. Differential stress values at point of highest curvature in stress-displacement curve are indicated. e) Mosaic of light micrographs, plane polarized light. Two faults are seen, forming a foliation in the adjacent host rock. f) and g) BSE SEM image close-up view of fault. (For interpretation of the references to colour in this figure legend, the reader is referred to the Web version of this article.) 

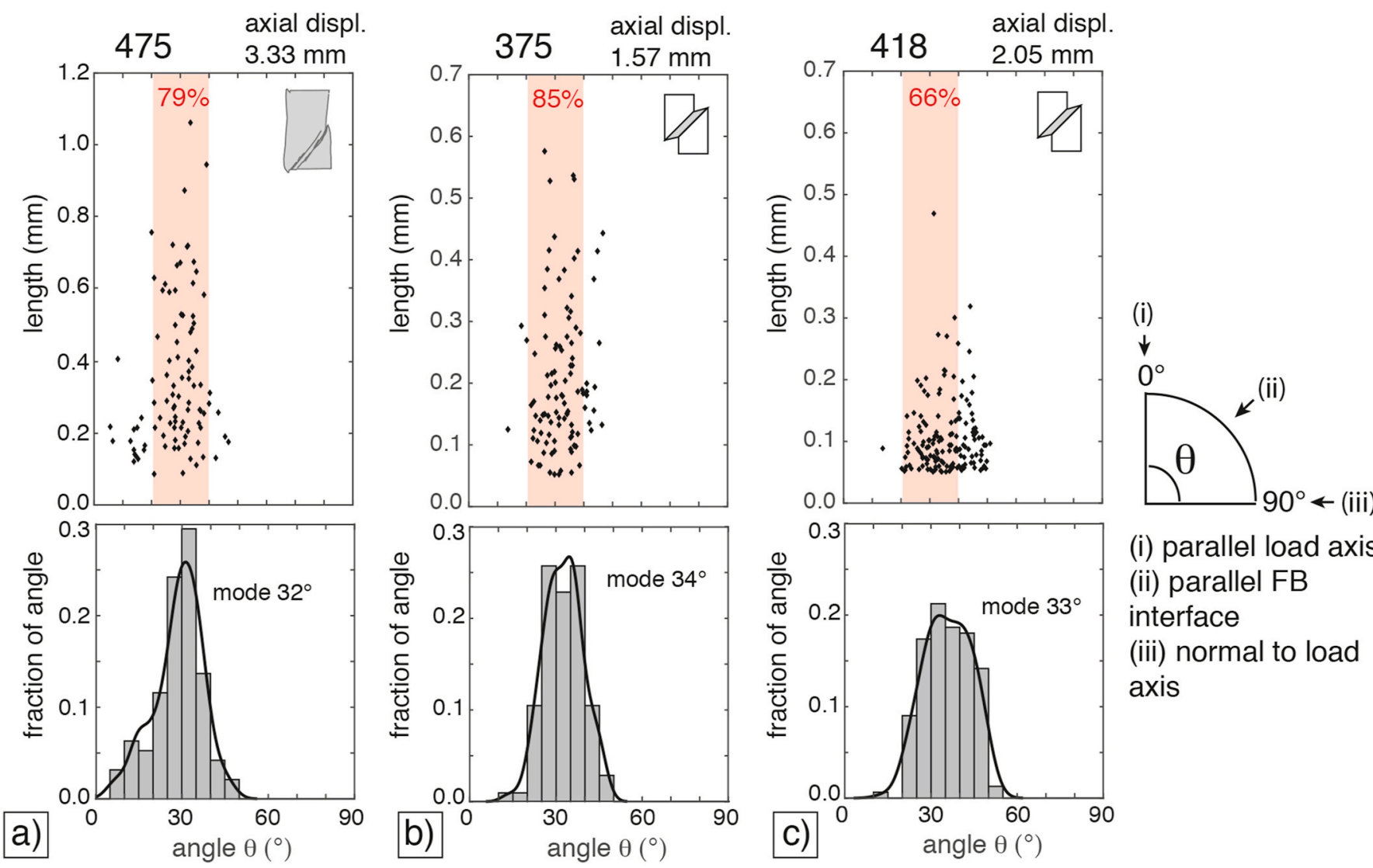

(i) parallel load axis (ii) parallel FB interface (iii) normal to load axis

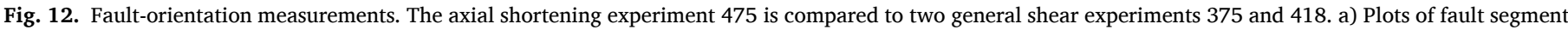

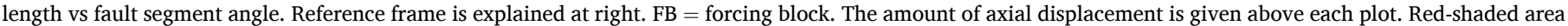

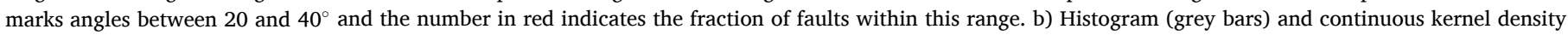

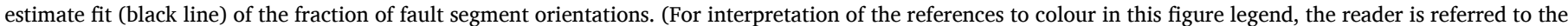
Web version of this article.)

frictional melting) is indicated by the following observations:

(i) While the amorphous type II shear bands are pervasive in $300{ }^{\circ} \mathrm{C}$ (0.5 GPa Pc) experiments after larger displacements, they are absent in samples deformed only to peak stress (Fig. 7). The peak stress sample (no. 421) indicates that initial localization of deformation occurs in ultra-cataclastic type I shear bands. It is interpreted that the initial type I shear bands evolve into type II shear bands with increasing displacement. A similar progressive development of partially amorphous to fully amorphous material has been documented by Pec et al. (2016) for granitoid rock material.

(ii) At higher Pc, both the ultra-cataclastic type I and the amorphous type II shear bands form less extensively and less frequently than at lower Pc (Fig. 10). This behavior is observed for all temperatures from 300 to $600{ }^{\circ} \mathrm{C}$. Increased Pc suppresses the formation of ultra-cataclasites, because cataclastic flow necessitates dilatancy. Suppressing the formation of ultra-cataclasites then leads to a decreased subsequent development of amorphous shear bands.

(iii) The geometry of shear bands formed in our experiments is seldom planar but irregular with many 'wavy' segments (e.g. Figs. 4 and 5). Pseudotachylites that are interpreted to have originated from frictional melting during seismic rupture are generally seen to be planar, even if the pseudotachylite boarders may be wavy from melt injection veins, etc. The undulatory geometry of shear bands in our samples does not favor fast slip, and points to an origin of coalescence rather than rupturing.

(iv) While the amorphous material in shear bands is almost exclusively derived from plagioclase (Fig. 8), biotite in the very close vicinity of the shear band does not show any indication of melting (Figs. 8e and 9). The liquidus temperature of intermediate plagioclase in the presence of water is $\sim$ at $1150{ }^{\circ} \mathrm{C}$ (Johannes, 1978). For biotite with an $\mathrm{Fe} /(\mathrm{Fe}+\mathrm{Mg})$ ratio of $\sim 0.35-0.43$, liquidus $\mathrm{T}$ is expected to be around $100{ }^{\circ} \mathrm{C}$ lower, at around 1040-1070 ${ }^{\circ} \mathrm{C}$ (Eugster, H. P., 1965). The fact that the biotite grain shown in Figs. 9 and $200 \mathrm{~nm}$ away from the shear band, is still crystalline and not molten strongly indicates that the temperatures were not high enough to melt either biotite or plagioclase.

Furthermore, nanocrystals of plagioclase and pyroxene are found in the amorphous layers (Fig. 8a and b) - if the temperature of the shear bands had reached melting conditions, the survival of such nano-crystals would have been highly unlikely due to their high surface energy.

\subsection{Temperature-sensitivity of amorphous shear bands}

The flow structures and high strain accommodation in the amorphous type II shear bands raise the question whether the material could be above its glass transition temperature at values as low as $300{ }^{\circ} \mathrm{C}$ (at the given experimental displacement rates, i.e. time scales). The flow structures and the temperature-sensitivity of sample strength indicate that deformation of the amorphous material is temperature sensitive. With increasing experimental T, the type II shear bands are observed to decrease in width and become more localized into fewer boundary shears. This behaviour would be consistent with a decreasing viscosity of the amorphous material at higher temperatures, allowing for greater strain localization. 
Although it is unlikely that frictional melting occurs in our experiments due to the slow rates of deformation, a limited temperature increase within shear bands due to shear heating is probable (e.g. Ben-Zion and Sammis, 2013; Duretz et al., 2015). In order to explore the possibility of frictional heating, we have designed a 'worst-case' scenario for shear strain concentration in the amorphous material (see Appendix A4) and calculated the intensification of the shear strain rate with respect to the shear strain rate of the bulk sample. We assume that the shear zone deforms homogeneously until peak stress is reached, and that, after peak stress, all of the deformation is taken up by a fault zone made up of all the shear bands in the sample while the rest of the shear zone stops deforming. The intensification depends on the ratio $(x=t h X /$ th 0$)$ between the thickness of the fault zone and that of the entire shear zone, and on the ratio $\left(\mathrm{f}=\mathrm{d}_{2} / \mathrm{d}_{1}\right)$ between the displacements before and after peak stress. Significant intensification is only possible, if the shear bands are very thin (see Appendix A4).

As seen in $2 \mathrm{D}$, the shear bands comprise 2 to 3.4 area $\%$ for the samples 375 and 418, respectively (Fig. 4c). For sample 375, $x \approx 0.02$ and $\mathrm{f} \approx 0.6$, the resulting intensification of the shear strain and shear strain rate is $19 \mathrm{x}$, while for sample 418 , with $\mathrm{x} \approx 0.034$ and $\mathrm{f} \approx 1.0$, the resulting intensification is $15 x$. For bulk sample strain rates of $\sim 3 \cdot 10^{-5}$ $\mathrm{s}^{-1}$, the corresponding shear strain rates in the amorphous layers are $\sim 6 \cdot 10^{-4} \mathrm{~s}^{-1}$ (375) and $\sim 5 \cdot 10^{-4} \mathrm{~s}^{-1}$ (418). Even if we assume that only $10 \%$ of the shear bands deform actively, the resulting strain rates would only be $\sim 6 \cdot 10^{-3} \mathrm{~s}^{-1}$ (375) and $\sim 5 \cdot 10^{-3} \mathrm{~s}^{-1}$ (418). Following the approach of Cardwell et al. (1978), temperature increase from frictional heating is calculated to be on the order of $4-7{ }^{\circ} \mathrm{C}$ (Appendix A5). This $\mathrm{T}$ increase may be a very conservative estimate, but even if the $T$ increase were one order of magnitude higher, it is far from sufficient to cause melting in the crystalline material. Still, given temperature-dependent viscosity, any $\mathrm{T}$ increase in the shear bands will lower the strength of the amorphous materials and favor continued strain localization.

\subsection{Fault network geometry and its influence on bulk sample strength}

The fault network formed in our experiments is always comprised of segments of shear fractures and segments of shear bands (either type I or type II or a combination of both, e.g., Fig. 10). However, in none of the experiments have we observed a through-going, fully connected amorphous type II shear band. This has two important implications: (a) the fault network does not completely detach the two sides of the shear zone-host system - bridges of cataclastic host rock remain, resisting displacement along the fault network; and (b) the mechanical strength of the network is not the same everywhere. Some segments must be weak because they deform viscously while others are strong due to frictional deformation ('creeping' vs. 'locked segments), as suggested e. g., by Pec et al. (2016). While our samples show this at a small scale, large scale segments of natural fault zones show this as well (e.g., Simon et al., 1985; Pacheco et al., 1993; Dixon and Moore, 2007; Scholz and Campos, 2012).

Additionally, shear bands and shear fractures commonly form at an angle of $20-40^{\circ}$ to the load axis (Fig. 12), inclined $5-25^{\circ}$ with respect to the forcing block interfaces. Due to this orientation relationship and the rigid nature of the forcing blocks, displacement along the shear bands is, at least in part, controlled by the deformation of the material in the lower strain regions between the bands. The resulting bulk sample strength thus is determined in part by the rheology of the stronger material in low strain regions, and the low strain regions deform mainly by cataclastic flow. Due to the discontinuity of amorphous shear bands and the inclination of shear band boundaries with respect to the forcing block, the bulk sample mechanical response is a mixture of viscously deforming shear bands, frictional sliding shear fractures, and cataclastic lower strain lenses. The implications of this observation is that the bulk mechanical sample response and the strength and temperature dependence of the amorphous zones only partially control sample strength, so that bulk sample strength would be far lower for the case of fully interconnected, favorably oriented amorphous shear bands (i.e. fully viscous instead of semi-brittle behaviour).

\subsection{Comparison with axial shortening experiment}

One axial shortening experiment (no. 475) on a solid intact sample was performed with the intention of observing how shear bands and fractures develop in the absence of an enforced geometry. The fault geometry of this sample is more complex, with several interfering conjugate sets of faults and with a major fault that ended at the interface with the bottom alumina piston (Fig. 11a, c). The hardening displayed by the mechanical data again indicates a mixed rheology of weaker fault zones and stronger low strain domains, which must both deform in order to accommodate bulk sample strain in the presence of non-continous, conjugate faults and their interaction with the bottom alumina piston. Minor hardening in the axial experiment versus minor weakening in the shear experiment (Fig. 11 d) may be due to sample geometry where faults are more effectively terminated at the cylindrical piston-sample interface (sample 475) as opposed to the $45^{\circ}$ interface in the shear assembly (sample 418).

With $0.8-0.9 \mathrm{~mm}$ axial displacement needed until the point of highest curvature is reached in the stress-displacement data, the displacement is comparable in both, general shear and axial shortening experiment (Fig. 11d). Importantly, the significantly smaller sample volume in the general shear sample compared to the axial shortening sample does not seem to have an influence on the bulk sample strength. Also, the developed microstructures in the axial shortening and the general shear experiments are very similar: the fault angle $\theta$ is between 20 and $40^{\circ}$ with respect to the load axis (Fig. 12), pervasive fracturing and cataclastic flow lead to a foliation in the wall rock adjacent to the faults. The faults show microstructural characteristics of type II shear bands throughout (Fig. 11f and g).

\subsection{Comparison with nature}

We performed our experiments to study the deformation behavior and rheology of semi-brittle fault rocks within mafic rocks. Two points should be noted: (i) the experiments are run without any significant amount of pore fluid pressure, and (ii) although the starting material represents a high-grade mafic assemblage that is metastable at the imposed experimental conditions, no significant amount of mineral reaction products were observed (probably due to sluggish reaction kinetics). Relating to nature, such a situation would correspond to a dry case or to the initiation of semi-brittle deformation when external fluids have not (yet) infiltrated the rock.

In our samples, amorphous material is considered to have formed as a result of intense crushing and mechanical wear. The amount of amorphous material formed is considered to be proportional to the work performed on the rock, i.e. the integral of the stress-strain curve. In our samples, amorphous shear bands are considered to form between peak stress (initial localization of intense crushing, Fig. 7) and the post-peak weakening. The estimated strain that is accumulated within shear bands until they become amorphous is around $\gamma \approx 10-20$ (see appendix A4 for calculation). Shear stresses in our experiments are high (on the order of several hundred MPa up to $\sim 1.2 \mathrm{GPa}$ ). In general, the stresses in the (semi-)brittle crust are assumed to be approximately 10-times lower than in our experiments (Bürgmann and Dresen, 2008; Behr and Platt, 2014), although, locally, stresses may rise to high levels in nature as well. If lower stresses are assumed for nature, amorphous material can still form at stress concentrations but will necessitate larger strains to generate equal amounts of amorphous material compared to our experiments. Evidence for such a stress - strain trade-off comes e.g. from observations from Yund et al. (1990), who observed amorphous material forming along faults within their experiments at far lower stresses (10s of MPa) than ours but at significantly higher strains (shear strains on the order of 100-1000). As the preservation potential of amorphous 
material in nature is likely to be low in the presence of aqueous fluids, it will easily be alterated and/or replaced by lower grade metamorphic assemblages and vanish from the geological record.

From our observations we suggest that amorphous material in brittle fault zoneshas the potential of introducing a temperature dependence (i. e. viscous component) to fault rock rheology, with lower fault strengths at higher temperatures. In nature, as in our experiments, the degree to which this viscous component will determine the bulk fault rheology depends on the geometric arrangement and the degree of connectivity of the amorphous material within the fault (c.f. Pec et al., 2016). The less favorable the geometrically orientation and/or the lower the connectivity of shear bands, the closer the bulk rheological response will be to a brittle end-member behavior.

Significant temperature effects on fault strength in our experiments are observed over a range of temperatures from 300 to $600{ }^{\circ} \mathrm{C}$. These are higher temperatures than generally assumed for brittle fault zones at natural conditions (usually around $\mathrm{T}<200{ }^{\circ} \mathrm{C}$ ). However, this has to be seen in relation to the fast experimental strain rates. For temperatureactivated processes, experiments are carried out at higher temperatures to compensate for a shorter duration. Viscous behavior in sections of natural fault systems caused by the presence of amorphous material at temperatures of $\sim 200{ }^{\circ} \mathrm{C}$ could be expected at the lower natural strain rates. Additionally, even a moderate temperature increase due to shear heating, during times of elevated fault creep rates, would favor strain localization in amorphous material as the material's deformability is temperature sensitive. The more strain is accommodated by amorphous material, the more likely is the fault rheology to diverge from a purely brittle behavior towards a more viscous rheology.

Our study shows that amorphous material can be present prior to a seismic event. It has been reported from several studies that pseudotachylites which formed during seismic rupture, could have initiated from a cataclastic stage (e.g. Magloughlin, 1992; Hetztel et al., 1996; Curewitz and Karson, 1999). As seen from our experiments, only a few $\mathrm{mm}$ of displacement are needed (at the high experimental differential stresses) to form amorphous material from plagioclase. Such amorphisation due to mechanical wear may form from an ultra-cataclastic stage.

The presence of amorphous materials along a fault (caused by earlier aseismic deformation) will be of importance during a seismic rupture event that has the potential of significantly increasing the local temperature due to shear heating. Where a fault heats up during rupturing, the strong temperature-sensitivity of the amorphous material will cause a significant strength drop of the fault and cause strain localization within the weakened amorphous material. Both effects will promote the continuation of seismic rupture, (i) by a strength reduction of the fault and (ii) by strain localization that will cause high stress concentrations at the tip of the deforming zone. As the glass transition temperature $\left(\mathrm{T}_{\mathrm{g}}\right)$ of an amorphous material usually is far below the melting temperature of a chemically equivalent crystalline solid, amorphous materials can significantly weaken a fault at temperatures below those needed for melting and melt-lubrication.

In our experiments, where amorphisation occurs by mechanical wear, feldspars are observed to be especially susceptible to amorphisation (see also Pec et al., 2011, 2012). Natural faults within feldspar-rich rocks may thus be the most likely candidates to show temperature-sensitive viscous behaviour. As feldspars are prone to fragmentation and amorphisation, a "crush-origin pseudotachylite" would be expected to show only small amounts of feldspar clasts. In contrast to a "melt-origin pseudotachylite", which may be likely to preserve plagioclase clasts due to incomplete melting.

\section{Conclusions}

The results of experiments using pre-crushed natural diabase at confining pressures of 0.5-1.0 GPa, temperatures between 300 and 600 ${ }^{\circ} \mathrm{C}$, and bulk displacement rates of $10^{-5}$ to $10^{-6} \mathrm{~s}^{-1}$ lead to the following conclusions:
- The bulk mechanical response of the sample contains attributes of both brittle (pressure-dependent) and viscous (temperature-dependent) deformation. Whereas the brittle deformation is correlated with widespread cataclastic flow, the viscous component is attributed to the formation of amorphous to nano-crystalline material within localized shear bands, especially at lower temperatures. At high temperatures $\left(\sim 600{ }^{\circ} \mathrm{C}\right)$, diffusion creep deformation is suggested to (partly) take over in fine-grained material.

- The amorphous material has formed due to mechanical wear from an ultra-cataclastic pre-stage - not due to frictional heating and melting. Amorphisation occurs after $\geq 0.9 \mathrm{~mm}$ of axial displacement on narrow zones of $\sim 2-20 \mu \mathrm{m}$ width during slow slip (aseismic slip rates). - The amorphous material is weaker than the surrounding, highly fractured crystalline material and decreases in strength with increasing temperatures. It introduces a temperature-sensitive viscous behavior in an otherwise cataclastically deforming rock.

- The degree to which the amorphous material in localized shear bands controls the bulk sample strength is determined by the geometrical arrangement of the shear bands and their degree of interconnection. In our experiments, the weakening induced by the formation of the amorphous material is considered to be far below the potential weakening it could produce. Shear bands are not fully interconnected and they are not oriented parallel to the shear zone boundaries such that they have not developed across entire samples. Thus, portions of the shear zones mechanically are not controlled by viscous shear within amorphous material but by cataclastic deformation. The result is a mixed mechanical response with both, temperature sensitive and pressure sensitive characteristics.

- Plagioclase is especially susceptible to amorphisation by mechanical wear and natural rocks composed of a high amount of plagioclase have the potential to form significant amounts of amorphous material.

- Due to its temperature-sensitivity, amorphous material is likely to have a significant influence on fault rock strength when temperatures are raised, as, for example, in the course of frictional heating during a seismic rupture event. Our experiments indicate that amorphous material can lead to weakening at temperatures as low as $300{ }^{\circ} \mathrm{C}$, indicating that significant fault weakening can occur at temperatures far below those where melting and melt-lubrication occurs.

\section{Declaration of competing interest}

The authors declare that they have no known competing financial interests or personal relationships that could have appeared to influence the work reported in this paper.

\section{CRediT authorship contribution statement}

Sina Marti: Investigation, Formal analysis, Visualization, Writing original draft. Holger Stünitz: Supervision, Funding acquisition, Writing - review \& editing, Investigation. Renée Heilbronner: Supervision, Project administration, Funding acquisition, Formal analysis, Writing - review \& editing. Oliver Plümper: Writing - review \& editing, Investigation.

\section{Acknowledgements}

We thank the team of the center of nano imaging (SNI) at Basel University for assistance with the electron microscopy. Terry Tullis is thanked for providing the Maryland Diabase material. Willy Tschudin is thanked for excellent thin section preparation. Very constructive reviews by Andreas Kronenberg and an anonymous reviewer have improved the present version of the manuscript. We gratefully acknowledge the funding provided by the Swiss National Founds grant NF 200020_144448. O.P. acknowledges his ERC starting grant 
The rock powder used in the general shear experiments was prepared by crushing Maryland Diabase rock pieces with a hand-press and subsequently with an alumina hand-mortar, repeatedly separating the size fraction $<125 \mu \mathrm{m}$. The sample, containing the alumina forcing blocks and the rock powder with the added $\mathrm{H}_{2} \mathrm{O}$, were wrapped with a nickel foil $(0.025 \mathrm{~mm}$ foil thickness) and placed in a pre-annealed platinum jacket ( $0.15 \mathrm{~mm}$ wall thickness). The jacket is weld-sealed with a Lambert welding apparatus, while the jacketed sample is held in a pre-cooled ( $\left.4{ }^{\circ} \mathrm{C}\right)$ sample-holder to prevent sample heating and water loss during welding. The sample prepared from a cored cylinder of intact Maryland Diabase was jacketed and sealed in the same way as the samples prepared from rock powder in the $45^{\circ}$ shear set-up. Potassium Iodide (KI) was used as the confining medium in an allsalt-assembly.

\section{A2. Mechanical data acquisition and data treatment}

Confining pressure (Pc), axial load and displacement of the load piston are recorded digitally at $1 \mathrm{~Hz}$. Temperature is measured via a thermocouple positioned next to the sample (Fig. 1a) and monitored and controlled (held within $\pm 1{ }^{\circ} \mathrm{C}$ ) with a PID Eurotherm controller. For all experiments, the axial displacement is corrected for apparatus stiffness ('stiffness correction'). Pc (i.e. $\sigma 3$ ) is corrected for the pressure increase in the confining medium, which is brought about by a volume decrease inside the pressure vessel due to the advancing load piston ('salt correction', Richter et al., 2016). For every $\mathrm{mm}$ piston advance, the volume of the confining medium inside the pressure vessel decreases by approximately $0.2 \%$. For example, if KI is used as a confining medium and a starting confining pressure of $10 \mathrm{~kb}$ is applied, the volume decrease gives rise to a pressure increase of approximately 20.3 to $16.9 \mathrm{MPa} / \mathrm{mm}$ for deformation temperatures of $300-600{ }^{\circ} \mathrm{C}$, respectively.

Differential stress $(\Delta \sigma)$ of general shear experiments is calculated for a constant cross section of the forcing block pistons (diameter $d=6.55 \mathrm{~mm}$ ) and subsequently corrected for the decreasing overlap of the forcing blocks with increasing displacement ('overlap correction', Fig. 1c, Marti et al., 2017 Eq. (2b)). The shear stress $(\tau)$ is derived from Mohr circle construction from the area corrected $\Delta \sigma$. For the axial shortening experiment, $\Delta \sigma$ is calculated in the usual manner by assuming an increasing cross sectional area of the sample (so-called 'area correction').

\section{A3. Fault zone orientation distribution}

Fractures and shear bands were segmented by manually tracing them from backscattered electron (BSE) and light microscope images (for general shear and for the axial shortening experiment respectively). The orientation of shear bands and shear fractures was determined using the 'Analyze Particle' function of the image analysis platform ImageJ. As especially shear bands can show an anastomosing trend and significant variations in local orientations, they were manually separated into approximately straight segments so that the true orientation of the individual segments could be measured and not an intermediate mean angle derived from measuring an anastomosing shear band as a whole. The minimum length of a structure measured in the case of the general shear experiments was set to $50 \mu \mathrm{m}$. To derive a mode orientation of the measured shear bands and shear fractures, a continuous kernel-density estimator function was fitted on the orientation distribution, using the MATLAB software and the MATLAB function 'ksdensity'.

\section{A4. Strain and strain rate estimates for shear bands}

From microstructural observations localization into ultra-cataclastic shear bands initiates at peak stress (in the mechanical data). The weakening after peak stress is correlated with the deformation of the amorphous material. Appendix Fig. 1 shows a typical stress displacement plot with, below, a schematic drawing of the shear strain partitioned between the cataclastic material of the shear zone ('host rock') and the amorphous material of the shear bands which are represented by a single layer ('fault zone').

The following simplifying assumptions are made: 1 . Thinning of the sample is neglected, its initial thickness remains th0 = constant. 2 . The displacement from start to peak stress $\left(\mathrm{d}_{1}\right)$ is achieved by homogeneous shear of the entire shear zone $\left(\gamma_{0}\right)$. 3. The remaining deformation after peak stress $\left(d_{2}\right)$ is achieved entirely by the fault zone (shear bands) $\left(\gamma_{\mathrm{FZ}}\right)$, the host rock stops deforming. 4 . As a consequence, the bulk shear strain of the sample as a whole (host rock plus fault zone) is $\gamma_{\mathrm{b}}=\left(\mathrm{d}_{1}+\mathrm{d}_{2}\right) /$ th0.

The aim is to find the ratio between the shear strain $\gamma_{\mathrm{FZ}}$ and $\gamma_{\mathrm{b}}$ as a function of the relative thickness of the shear zone $(\mathrm{x}=$ thX/th0) and the relative length of displacement after peak stress $\left(\mathrm{f}=\mathrm{d}_{2} / \mathrm{d}_{1}\right)$.

$\gamma_{\mathrm{FZ}}=\left(\mathrm{d}_{1}+\mathrm{d}_{1}-\mathrm{w}\right) /$ thX

Where $\mathrm{w}=\left(\mathrm{h} \cdot \gamma_{0}\right), \mathrm{h}=($ th0 - thX $), \gamma_{0}=\left(\mathrm{d}_{1} /\right.$ th0 $)$, and thX $=(\mathrm{x} \cdot$ th0 $)$. Replacing yields

$\gamma_{\mathrm{FZ}}=\left(\mathrm{d}_{1}+\mathrm{d}_{2}-(\right.$ th $0-$ thX $) \cdot\left(\mathrm{d}_{1} /\right.$ th 0$\left.)\right) /(\mathrm{x} \cdot$ th 0$)$

Regrouping and replacing $d_{2}=\left(f \cdot d_{1}\right)$ yields 
$\gamma_{\mathrm{FZ}}=\left(\mathrm{d}_{2}+\mathrm{x} \cdot \mathrm{d}_{1}\right) /(\mathrm{x} \cdot$ th 0$)=\left((\mathrm{f}+\mathrm{x}) \cdot \mathrm{d}_{1}\right) /(\mathrm{x} \cdot$ th0 $)$

and finally

$\gamma_{\mathrm{FZ}}=((\mathrm{f}+\mathrm{x}) / \mathrm{x}) / \gamma_{0}$

Appendix Table 1 lists ratios of $\left(\gamma_{\mathrm{FZ}}: \gamma_{0}\right)$ and $\left(\gamma_{\mathrm{FZ}}: \gamma_{\mathrm{b}}\right)$ for shear zones as they occur typically in the experiments discussed here. The displacements before and after peak stress, $d_{1}=d_{2}=1 \mathrm{~mm}$, as a consequence, $(\mathrm{f}=1)$. The shear zone thickness, th $0=0.8 \mathrm{~mm}$, as a consequence, $\left(\gamma_{0}=1.25\right.$ and $\gamma_{\mathrm{b}}=$ 2.5). A range of values for the relative thickness of the fault zone is used $(0<\mathrm{x} \leq 1.00)$.

\begin{tabular}{lll}
$\begin{array}{ll}\text { Appendix Table } \mathbf{1} \\
\text { thX: th0 }\end{array}$ & & \\
\hline 0.0001 & $\gamma_{\mathrm{FZ}}: \gamma_{0}$ & $\gamma_{\mathrm{FZ}}: \gamma_{\mathrm{b}}$ \\
0.0010 & 10001 & 5001 \\
0.0100 & 1001 & 500 \\
0.0500 & 101 & 50 \\
0.1000 & 21 & 11 \\
0.5000 & 11 & 5 \\
1.0000 & 3 & 2 \\
\hline
\end{tabular}

\section{A5. Shear heating estimate}

An estimate for the amount of shear heating reached in our experiments is derived after the model from Cardwell et al. (1978). The authors suggest that if the width of the fault is much smaller compared to the characteristic length for heat conduction, i.e. $w /(\kappa \cdot t)^{1 / 2} \ll 1$ (where $w$ is fault width, $\kappa$ is thermal diffusivity and $t$ is the duration of slip) the temperature difference caused by frictional heating equates to

$\Delta T=\frac{\tau \cdot D}{\rho \cdot c_{p} \cdot \sqrt{\pi \kappa t}}$

$\tau=$ shear stress $[\mathrm{Pa}], D=$ fault displacement $[\mathrm{m}], \rho=$ density $\left[\mathrm{kg} / \mathrm{m}^{3}\right]$, and $c_{p}=$ specific heat capacity $[\mathrm{J} / \mathrm{kgK}]$.

We consider the cases of four experiment at 300 and $600{ }^{\circ} \mathrm{C}$ and both confining pressures (Appendix Table 2). For a minimum estimate, we assume the active shear band to have a width of $1 \%$ of the total shear zone width (th0), thus $\mathrm{w}=0.8 \mathrm{~mm} * 0.01=8 \mathrm{e}-6 \mathrm{~m}$. For the duration of slip we take the time between peak stress to the end of the experiment and for $\kappa$ we use published data from Branlund and Hofmeister, 2012) (Appendix Table 3). For $w /(\kappa \cdot t)^{1 / 2}$, we thus receive values between $6.1 \mathrm{e}-05$ and $4.0 \mathrm{e}-05$, fulfilling the condition that the fault width is much smaller than the characteristic length of head conduction.

The temperature difference is calculated using equation (A5), using values given in Appendix Table 3. Specific heat capacity values are converted from $\mathrm{J} / \mathrm{mol}^{*} \mathrm{~K}$ to $\mathrm{J} / \mathrm{kg} * \mathrm{~K}$ by $c_{p}(\mathrm{~J} / \mathrm{kg} \cdot \mathrm{K})=c_{p}(\mathrm{~J} / \mathrm{J} \cdot \mathrm{K}) \cdot \frac{1}{\rho} \cdot \frac{1}{m}$ where $m$ is the plagioclase mole volume and $\rho$ is the plagioclase density. If we consider a maximum estimate where we use peak stress for the whole length of the fault displacement, then temperature increase values range between 5.3 and $7.2{ }^{\circ} \mathrm{C}$ for the $300{ }^{\circ} \mathrm{C}$ experiments and $5.4-4.4{ }^{\circ} \mathrm{C}$ for the $600{ }^{\circ} \mathrm{C}$ experiments. These numbers are significantly away from a temperature increase that could cause melting in our experiments.

Appendix Table 2

\begin{tabular}{|c|c|c|c|c|c|c|}
\hline Sample & $\mathrm{T}$ & Pc & peak tau & average tau & shear disp & shear time \\
\hline 509 & $300{ }^{\circ} \mathrm{C}$ & $0.5 \mathrm{GPa}$ & $1069 \mathrm{MPa}$ & $985 \mathrm{MPa}$ & $0.9359 \mathrm{~mm}$ & $34185 \mathrm{~s}$ \\
\hline 373 & $600^{\circ} \mathrm{C}$ & $0.5 \mathrm{GPa}$ & $614 \mathrm{MPa}$ & $479 \mathrm{MPa}$ & $1.5062 \mathrm{~mm}$ & $64220 \mathrm{~s}$ \\
\hline 395 & $300{ }^{\circ} \mathrm{C}$ & $1.0 \mathrm{GPa}$ & $1318 \mathrm{MPa}$ & $1129 \mathrm{MPa}$ & $1.2052 \mathrm{~mm}$ & $47025 \mathrm{~s}$ \\
\hline 399 & $600^{\circ} \mathrm{C}$ & $1.0 \mathrm{GPa}$ & $930 \mathrm{MPa}$ & $748 \mathrm{MPa}$ & $1.5756 \mathrm{~mm}$ & $67404 \mathrm{~s}$ \\
\hline
\end{tabular}

Appendix Table 3

\begin{tabular}{|c|c|c|c|c|c|}
\hline \multicolumn{2}{|c|}{$\kappa\left(\mathrm{m}^{2} / \mathrm{s}\right)^{*}$} & \multicolumn{2}{|c|}{$\mathrm{c}_{\mathrm{p}}(\mathrm{J} / \mathrm{mol} \bullet \mathrm{K})^{* *}$} & \multirow[t]{2}{*}{$\rho\left(\mathrm{kg} / \mathrm{m}^{3}\right)$} & \multirow[t]{2}{*}{$\mathrm{mol}$ vol $\left(\mathrm{m}^{3} / \mathrm{mol}\right)$} \\
\hline at $300{ }^{\circ} \mathrm{C}$ & at $600^{\circ} \mathrm{C}$ & at $300{ }^{\circ} \mathrm{C}$ & at $600^{\circ} \mathrm{C}$ & & \\
\hline $5.9010^{-7}$ & $5.0310^{-7}$ & 274.8173 & 304.8721 & 2710 & 101 \\
\hline
\end{tabular}

* data from Branlund and Hofmeister (2012).

** data from Hemingway et al. (1981) 

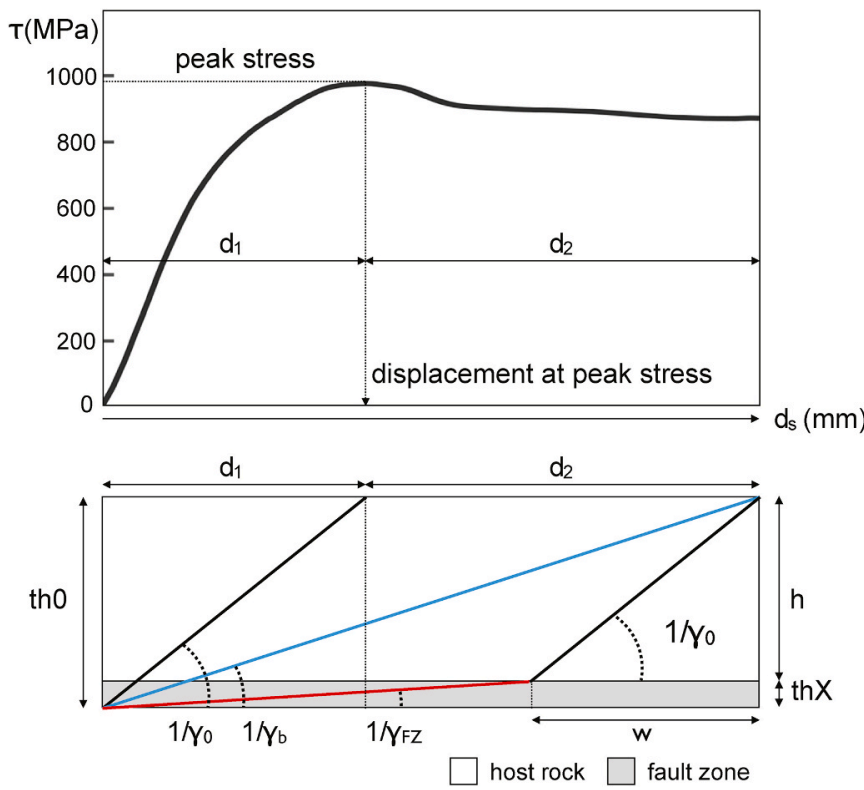

Appendix Fig. 1. Strain partitioning in shear zone. Above: Typical stress-strain plot of a shearing experiment: shear stress $(\tau)$ versus shear displacement $\left(d_{s}\right)$. Below: Schematic drawing depicting the relative contributions of the cataclastically deforming shear zone ('host rock') and the amorphous material ('fault zone') to the total shear strain of the sample: $d_{s}=$ total displacement, $d_{1}=$ displacement before peak stress, $d_{2}=$ displacement after peak stress, th $0=$ initial thickness of sheazone, $\gamma_{0}=$ homogeneous shear strain achieved by entire sample before peak stress, $\gamma_{\mathrm{FZ}}=$ homogeneous shear strain achieved by fault zone, $\gamma_{\mathrm{b}}=$ heterogeneous shear strain achieved by entire sample (host rock plus fault zone), thX $=$ thickness of fault zone, $h=$ th $0-$ thX, $w=h \cdot \gamma_{0}$.

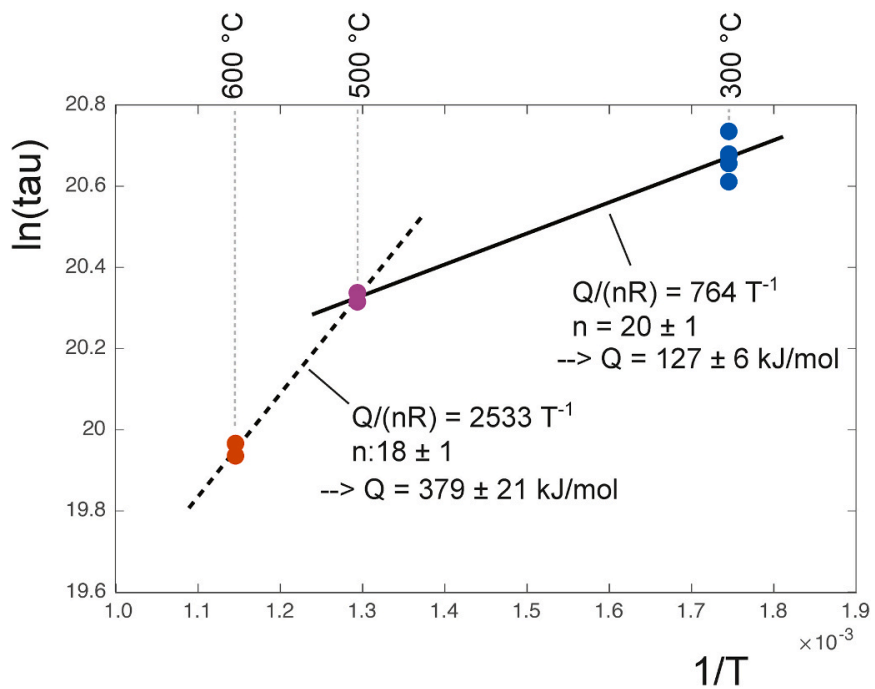

Appendix Fig. 2. Activation energies determined for experiments at Pc $=0.5 \mathrm{GPa}$ and two temperature ranges, $300-500{ }^{\circ} \mathrm{C}$ and $500-600{ }^{\circ} \mathrm{C}$. Stress exponent (n) values are taken from Marti et al. (2017). $Q=$ activation energy $[\mathrm{J} /$ mole $], R=$ universal gas constant $\left[\mathrm{J}\right.$ mole $\left.\mathrm{e}^{-1} \mathrm{~K}^{-1}\right], \mathrm{n}=$ stress exponent. Data is plotted as natural logarithm of average flow stress versus $\mathrm{T}^{-1}\left[{ }^{\circ} \mathrm{K}\right]$.

\section{References}

Anderson, O.L., Grew, P.C., 1977. Stress corrosion theory of crack propagation with applications to geophysics. Rev. Geophys. Space Phys. 151, 77-104.

Austrheim, H., Andersen, T.B., 2004. Pseudotachylytes from Corsica: fossil earth- quakes from a subduction complex. Terra. Nova 16, 193-197.

Ben-Zion, Y., Sammis, C.G., 2013. Shear heating during distributed fracturing and pulverization of rocks. Geology 412, 139-142.

Behr, W.M., Platt, J.P., 2014. Brittle faults are weak, yet the ductile middle crust is strong: implications for lithospheric mechanics. Annu. Rev. Earth Planet Sci. 36, $531-567$.

Blanpied, M.L., Lockner, D.A., Byerlee, J.D., 1995. Frictional slip of granite at hydrothermal conditions. JGR 100 B7, 12045-13064. https://doi.org/10.1029/ 95JB00862.

Bos, B., Spiers, C.J., 2001. Experimental investigation into the microstructural and mechanical evolution of phyllosilicate-bearing fault rock under conditions favouring pressure solution. J. Struct. Geol. 23 (8), 1187-1202. https://doi.org/10.1016/ S0191-81410000184-X.
Bos, B., Spiers, C.J., 2002. Fluid-assisted healing processes in gouge-bearing faults: insights from experiments on a rock analogue system. Pure Appl. Geophys. 159, 2537-2566. https://doi.org/10.1007/s00024-002-8747-2.

Branlund, J.M., Hofmeister, A.M., 2012. Heat transfer in plagioclase feldspars. Am. Mineral. 97, 1145-1154.

Brantut, N., Heap, M.J., Meredith, P.G., Baud, P., 2013. Time-dependent cracking and brittle creep in crustal rocks: a review. J. Struct. Geol. 52, 17-43.

Bürgmann, R., Dresen, G., 2008. Rheology of the lower crust and upper mantle: evidence from rock mechanics, geodesy, and field observations. Annu. Rev. Earth Planet Sci. $36,531-567$.

Byerlee, J.D., 1968. Brittle-ductile transition in rocks. J. Geophys. Res. 73, 4741-4750. Camacho, A., Vernon, R.H., Fitz Gerald, J.D., 1995. Large volumes of anhy- drous pseudotachylyte in the Woodroffe Thrust, eastern Musgrave Ranges, Australia. J. Struct. Geol. 173, 371-383.

Cardwell, R.K., Chinn, D.S., Moore, G.F., Turcotte, D.L., 1978. Frictional heating on a fault zone with finite thickness. Geophys. J. Roy. Astron. Soc. 52, 525-530. 
Chester, F.M., Higgs, N.G., 1992. Multimechanism friction constitutive model for ultrafine quartz gouge at hypocentral conditions. JGR 97B2, 1859-1870. https:// doi.org/10.1029/91JB02349.

Curewitz, D., Karson, J.A., 1999. Ultracataclasis, sintering, and frictional melting in pseudotachylytes from East Greenland. J. Struct. Geol. 21, 1693-1731.

Del Gaudio, P., Di Toro, G., Han, R., Hirose, T., Nielsen, S., Shimamoto, T., Cavallo, A.,

2009. Frictional melting of peridotite and seismic slip. J. Geophys. Res. 114B06306. D

Toro, G., Hirose, T., Nielsen, S., Shimamoto, T., 2006. Relating high-velocity rock-

friction experiments to coseismic slip in the presence of melts. In: Abercrombie, R., McGarr, A., Di Toro, G., Kanamori, H. (Eds.), Radiated Energy and the Physics of Faulting, Volume 170 of Geophysical Monograph. AGU, pp. 121-134.

Di Toro, G., Nielsen, S., Pennacchioni, G., 2005. Earthquake rupture dynamics frozen in exhumed ancient faults. Nature 436, 1009-1012.

Dingwell, D.B., Webb, S.L., 1989. Structural relaxation in silicate melts and nonNewtonian melt rheology in geologic processes. Phys. Chem. Miner. 16, 508-516.

Dixon, T.H., Moore, J.C., 2007. The seismogenic zone of subdution thrust faults. In: MARGINS Theoretical and Experimental Earth Science Series. Columbia University Press. https://doi.org/10.7312/dixo13866.

Duretz, T., Schmalholz, S.M., Podladchikov, Y.Y., 2015. Shear heating-induced strain localization across the scales. Phil. Mag. 95, 28-30.

Eugster, H.P., 1965. Stability of biotite: experiment, theory, and application. Am. Mineral. 50, 1228-1272.

Goldsby, D., Tullis, T.E., 2002. Low frictional strength of quartz rocks at subseismic slip rates. Geophys. Res. Lett. 2917, L015240.

Gratier, J.-P., Gueydan, F., 2008. In: Handy, M.R., Hirth, G., Hovius, N. (Eds.), Deformation in the Presence of Fluids and Mineral Reactions: Effect of Fracturing and Fluid-Rock Interaction on Seismic Cycles. The Dynamics of Fault Zones. The MIT Press, Mass., USA.

Gratier, J.-P., Renard, F., Labaume, P., 1999. How pressure solution creep and fracturing processes interact in the upper crust to make it behave in both a brittle and viscous manner. J. Struct. Geol. 21, 1189-1197.

Hayward, K.S., Cox, S.F., Fitz Gerald, J.D., Slagmolen, J.J., Shaddock, D.A., Forsyth, P.W F., Salmon, M.L., Hawkins, R., 2016. Mechanical amorphization, flash heating, and frictional melting: dramatic changes to fault surfaces during the first millisecond of earthquake slip. Geology 4412, 1043-1046.

Hetztel, R., Altenberger, U., Strecker, M.R., 1996. Structural and chemical evolution of pseudotachylytes during seismic events. Mineral. Petrol. 58, 33-50.

Hirose, T., Shimamoto, T., 2005. Growth of molten zone as a mechanism of slip weakening of simulated faults in gabbro during frictional melting. J. Geophys. Res. 110, B05202.

Janssen, C., Wirth, R., Rybacki, E., Naumann, R., Kemnitz, H., Wenk, H.-R., Dresen, G., 2010. Amorphous material in SAFOD core samples San Andreas Fault: evidence for crush-origin pseudotachylytes? Geophys. Res. Lett. 37, L01303.

Johannes, W., 1978. Melting of plagioclase in the system Ab-an- $\mathrm{H}_{2} \mathrm{O}$ and qz-ab-an- $\mathrm{H}_{2} \mathrm{O}$ at $\mathrm{P}_{\mathrm{H} 2 \mathrm{O}}=5$ kbars, an equilibrium problem. Contrib. Mineral. Petrol. 66, 295-303.

Kirkpatrick, J.D., Rowie, C.D., White, J.C., Brodsky, E.E., 2013. Silica gel formation during fault slip: evidence from the rock record. Geology 419, 1015-1018.

Kohlstedt, D.L., Evans, B., Mackwell, S.J., 1995. Strength of the Litosphere: constraints imposed by laboratory experimetns. J. Geophys. Res. Solid Earth 100B9, 517-587.

Magloughlin, J.F., 1992. Microstructural and chemical changes associated with cataclasis and frictional melting at shallow crustal levels: the cataclasite - pseudotachylyte connection. Tectonophysics 2043-4, 243-260.

Marti, S., Stünitz, H., Heilbronner, R., Plümper, O., Drury, M., 2017. Experimental investigation of the brittle-viscous transition in mafic rocks - interplay between fracturing, reaction, and viscous deformation. J. Struct. Geol. 105, 62-79.

Marti, S., Stünitz, H., Heilbronner, R., Plümper, O., Kilian, R., 2018. Syn-kinematic hydration reactions, grain size reduction, and dissolution-precipitation creep in experimentally deformed plagioclase - pyroxene mixtures. Solid Earth 94, 985-1009. https://doi.org/10.5194/se-9-985-2018.
Mc Kenzie, D., Brune, J.N., 1972. Melting on fault planes during large earthquakes. Geophys. J. Roy. Astron. Soc. 29, 65-78.

Niemeijer, A., Di Toro, G., Griffith, W.A., Bistacchi, A., Smith, S.A., Nielsen, S., 2012. Inferring earthquake physics and chemistry using an integrated field and laboratory approach. J. Struct. Geol. 39, 2-36.

Niemeijer, A., Di Toro, G., Nielsen, S., Di Felice, F., 2011. Frictional melting of gabbro under extreme experimental conditions of normal stress, acceleration, and sliding velocity. J. Geophys. Res. 116, B07404.

Obata, M., Karato, S.-I., 1995. Ultramafic pseudotachylite from the Balmuccia peridotite, Ivrea-Verbano zone, northern Italy. Tectonophysics 242, 313-328.

Ojovan, M.I., 2008. Viscosity and glass transition in amorphous oxides. Adv. Condens. Matter Phys., 817829 https://doi.org/10.1155/2008/817829, 2008.

Pacheco, J.F., Sykes, L.R., Scholz, C.H., 1993. Nature of seismic coupling along simple plate boundaries of the subduction type. J. Geophys. Res. 98, 14'133-14'159.

Paterson, M.S., Wong, T.-f., 2005. Experimental Rock Deformation - The Brittle Field. Springer, Berlin, Heidelberg. https://doi.org/10.1007/b137431.

Pec, M., Stünitz, H., Heilbronner, R., 2011. Semi-brittle deformation of grani- toid gouges in shear experiments at elevated pressures and temperatures. J. Struct. Geol. 38, $200-221$.

Pec, M., Stünitz, H., Heilbronner, R., Drury, M., de Capitani, C., 2012. Origin of pseudotachylites in slow creep experiments. Earth Planet Sci. Lett. 355 - 356, 299-310.

Pec, M., Stünitz, H., Heilbronner, R., Drury, M., 2016. Semi-brittle flow of granitoid fault rocks in experiments. J. Geophys. Res. Solid Earth 121. JB012513.

Philpotts, A.R., 1964. Origin of pseudotachylites. Am. J. Sci. 262, 1008-1035.

Richter, B., Stünitz, H., Heilbronner, R., 2018. The brittle-to-viscous transition in polycrystalline quartz: an experimental study. J. Struct. Geol. 114, 1-21.

Richter, B., Stünitz, H., Heilbronner, R., 2016. Stresses and pressures at the quartz- to coesite phase transformation in shear deformation experiments. J. Geophys. Res. Solid Earth 121, 8015-8033.

Rutter, E.H., 1968. On the nomenclature of mode of failure transitions in rocks. Tectonophysics 1223-4, 381-387.

Sanchez, E.C., Torres, E.M., Diaz, C., Saito, F., 2004. Effects of grinding of the feldspar in the sintering using a planetary ball mill. J. Mater. Process. Technol. 152, 284-290.

Scambelluri, M., Pennacchioni, G., Gilio, M., Bestmann, M., Plümper, O., Nestola, F., 2017. Fossil intermediate-depth earthquakes in subducting slabs linked to differential stress release. Nat. Geosci. 10 12, 960.

Schmid, S.M., Handy, M.R., 1991. Towards a genetic classification of fault rocks: geological usage and tectonophysical implications. In: Müller, D.W., Mc Kenzie, J.A., Weissert, H. (Eds.), Controversies in Modern Geology. Academic Press, London.

Scholz, C.H., Campos, J., 2012. The seismic coupling of subduction zones revisited. J. Geophys. Res. 117, B05310.

Sibson, R.H., 1975. Generation of pseudotachylyte by ancient seismic faulting. Geophys. J. Int. 433, 775-794.

Simon, T.T., Dmowska, R., Rice, J.R., 1985. Stressing of locked patches along a creeping fault. Bull. Seismol. Soc. Am. 753, 709-736.

Spray, J.G., 1987. Artificial generation of pseudotachylite using friction welding apparatus: simulation of melting on a fault plane. J. Struct. Geol. 9, 49-60.

Stünitz, H., Fitz Gerald, J.D., Tullis, J., 2003. Dislocation generation, slip systems, and dynamic recrystallization in experimentally deformed plagioclase single crystals. Tectonophysics 372, 215-233.

Twiss, R.J., Moores, E.M., 2007. Structural Geology, second ed. https://doi.org/ 10.1017/S0016756808004627 New York.

Verbene, B.A., Plümper, O., Spiers, C.J., 2019. Nanocrystalline principal slip zones and their role in controlling crustal fault rheology. Minerals 9, 328. https://doi.org/ 10.3390/min9060328.

Wenk, H.R., 1978. Are pseudotachylites products of fracture or fusion? Geology 68, 507-511.

Yund, R.A., Blanpied, M.L., Tullis, T.E., Weeks, J.D., 1990. Amorphous material in high strain experimental fault gauges. J. Geophys. Res. 95B10, 15589-15602. 